\title{
Multiple Attributes Group Decision-Making Approaches Based on Interval-Valued Dual Hesitant Fuzzy Unbalanced Linguistic Set and Their Applications
}

\author{
Xiaowen Qi (D), ${ }^{1}$ Junling Zhang, ${ }^{2}$ and Changyong Liang ${ }^{3}$ \\ ${ }^{1}$ School of Business Administration, Zhejiang University of Finance \& Economics, Hangzhou, Zhejiang 310018, China \\ ${ }^{2}$ School of Economics and Management, Zhejiang Normal University, Jinhua, Zhejiang 321004, China \\ ${ }^{3}$ School of Management, Hefei University of Technology, Hefei, Anhui 230009, China \\ Correspondence should be addressed to Xiaowen Qi; qixiaowen@zufe.edu.cn
}

Received 28 May 2017; Revised 1 November 2017; Accepted 9 November 2017; Published 22 April 2018

Academic Editor: Daniela Paolotti

Copyright (C) 2018 Xiaowen Qi et al. This is an open access article distributed under the Creative Commons Attribution License, which permits unrestricted use, distribution, and reproduction in any medium, provided the original work is properly cited.

\begin{abstract}
Aiming at multiple attributes group decision-making (MAGDM) problems that characterize uncertainty nature and decision hesitancy, firstly, we propose the interval-valued dual hesitant fuzzy unbalanced linguistic set (IVDHFUBLS) in which two sets of interval-valued hesitant fuzzy membership degrees and nonmembership degrees are employed to supplement the most preferred unbalanced linguistic term, as an effective hybrid expression tool to elicit complicate preferences of decision-makers more comprehensively and flexibly than existing tools based on classic linguistic term set. Basic operations for IVDHFUBLS are further defined; also a novel distance measure is developed to avoid potential information distortion that could be brought about by traditional complementing methodology for hesitant fuzzy set and its derivatives. In view of the fundamental role of aggregation operators in MAGDM modelling, we next develop some extended power aggregation operators for IVDHFUBLS, including power aggregation operator, weighted power aggregation operator, and induced power ordered weighted aggregation operator; their desirable properties and special cases are also analyzed theoretically. Subsequently, with support of the above methods, we develop two effective approaches for our targeted complex decision-making problems and verify their effectiveness and practicality by numerical studies.
\end{abstract}

\section{Introduction}

Aiming at improving competitiveness and business performance in volatile and unpredictable market environments, firms are always required to achieve product innovativeness by exploiting power of organizations [1]. Complexity theory perceives the organizations as complex adaptive systems (CAS) [2] and treats activities of product innovation as their responses to changing competitive environments [3]. Obviously, product design plays a vital role in firms' innovative research [4]; thus Chiva-Gomez [3] proposed four fundamental instructions for effective product design management from perspective of CAS, including (i) fostering a mechanism to obtain information from outside environments, (ii) fostering collaboration among designing and nondesigning agents in a firm, (iii) maximizing information flow in both quantitative and qualitative formation, and (iv) promoting heterogeneous participation during design decision-making.

In alignment with these instructions, customer-centric strategy has been integrated with intelligent decision-making systems [5] to achieve better understanding of customers' preferences and requirements from outside markets $[6,7]$. Representatively, Brintrup et al. [8] developed an ergonomic design system based on interactive genetic algorithms (IGA) which can include customers or other participators in product design to provide preferences as qualitative inputs. Mok et al. [6] studied a customized fashion design system where IGA were employed to construct fashion design sketches. Dou et al. [9] constructed a collaborative product design system in which they used interval fitness values to depict customers' decision hesitancy. Although these intelligent design systems provide platforms that incorporate customers' preferences as 
guidance of IGA to search optimal design alternatives, rigid preference expressions as crisp values [6-8] or interval values [9] apparently are incapable of effectively eliciting complicate opinions of customers and thus cannot maximize qualitative information flow from customers to organizations [3]. In addition, to accommodate heterogeneous participation in activity of design evaluation, proper group decision-making (GDM) approaches should also be developed and integrated.

Actually, the methodologies of multiple attributes group decision-making (MAGDM) [10,11] are capable of providing effective approaches to product design evaluation in the above-mentioned intelligent interactive systems, especially for scenarios that inevitably rely on participators' qualitative assessments, such as those fuzzy MAGDM approaches based on fuzzy set and its extensions $[12,13]$ and those approaches based on linguistic variables [14, 15]. In order to maximize qualitative information flow [3] into the intelligent design systems through helping participators express their real assessments more accurately and completely, linguistic variables attain greater efficiency than fuzzy numbers by direct use of natural language and thus are capable of relieving user fatigue [6-8] during iterative interaction in intelligent design systems. In literature, most linguistic MAGDM approaches were developed based on rigidly uniform or symmetrical linguistic term sets $[14,15]$; however, practical studies $[16,17]$ have revealed that decision-makers are inclined to express their complicate assessments more precisely and objectively by use of nonuniform or asymmetric linguistic term set, that is, the unbalanced linguistic term set (ULTS) [18]. Meng and Pei [19] and Dong et al. [20] investigated MAGDM approaches based on ULTS and verified that ULTS attains better adaptability and flexibility. Nevertheless, regarding the decision hesitancy $[21,22]$ revealed during users' evaluation in intelligent design systems [9], there is still a lack of investigation on preference expression tools that manage to take advantage of ULTS and simultaneously address decision hesitancy.

Therefore, in this paper, on the strength of ULTS and dual hesitant fuzzy set [23], we develop a hybrid preference expression tool, called interval-valued dual hesitant fuzzy unbalanced linguistic set (IVDHFUBLS). IVDHFUBLS holds a compound element structure of $(x, s, \widetilde{h}(x), \widetilde{g}(x))$ that comprises the most preferred unbalanced linguistic term $s$ and its supplementing interval-valued dual hesitant fuzzy element in which $\widetilde{h}(x)$ and $\widetilde{g}(x)$ are two interval-valued fuzzy sets for denoting possible membership and nonmembership degrees of evaluating fuzzy object $x$ to $s$. IVDHFUBLS is capable of not only depicting fuzzy properties of evaluating object to the designated linguistic term more completely, but also attaining flexibility in fitting various complex decisionmaking scenarios.

When MAGDM tackles various decision-making scenarios of high uncertainty, aggregation operators play an imperative role in support of computing with complicate preference expressions [24,25], such as weighted aggregation operators [26], ordered weighted aggregation operators [27], hybrid operators, and $\lambda$-generalized operators [28]. Especially, regarding those complex fashion design evaluation problems that heavily rely on human judgements and assessments [5], interdependences among attribute usually exist [29], and weighting information for participators from inside of firm organizations and outside customers cannot be determined in advance [30]. The power average aggregation operators proposed by Yager [31] are capable of objectively determining unknown weighting information by utilizing supportive interrelations among attribute values, thus providing a fundamental effective way to model practical complex problems. Since then, the practicality and effectiveness of power average operator have been verified under different decision-making situations [11, 32, 33]. Moreover, when the group of participators reach additional decision information, such as agreed ideal solutions and partial relations among attributes, Yager's induced aggregation operator [34] perceives those important information as order-inducing vectors and thus enables its based MAGDM approaches to exploit decision scenarios more completely than other classic methodologies $[34,35]$.

Consequently, in order to construct effective MAGDM approaches based on our newly proposed expression tool of IVDHFUBLS, we further focus on developing power average aggregation operators and induced aggregation operators for IVDHFUBLS, including a weighted interval-valued dual hesitant fuzzy unbalanced linguistic power aggregation (WIVDHFUBL-PA) operator, an interval-valued dual hesitant fuzzy unbalanced linguistic power aggregation (IVDHFUBLPA) operator, and an induced interval-valued dual hesitant fuzzy unbalanced linguistic power ordered weighted aggregation (I-IVDHFUBL-POWA) operator. Then we analyze their desirable properties and discuss their special cases. Furthermore, to avoid potential information distortion which could be brought forward by conventional complementing measures [36, 37], we also develop a novel distance measure for IVDHFUBLS. Subsequently, on the strength of the abovedeveloped aggregation operators and distance measure, two effective approaches are constructed to tackle MAGDM with uncertainty and decision hesitancy.

The remainder of this paper is organized as follows. Section 2 briefly reviews some preliminary conceptions. Section 3 defines the hybrid expression tool of interval-valued dual hesitant fuzzy unbalanced linguistic set (IVDHFUBLS), for which operational rules and a new distance measure are studied. Further, we investigate some power aggregation operators for IVDHFUBLS and their properties as well as special cases. In Section 4, two MAGDM approaches based on the developed power aggregation operators are constructed in detail; we then conduct numerical studies to verify effectiveness and practicality of the proposed approaches. Finally, conclusions and future research directions are given in Section 5.

\section{Preliminaries}

\subsection{Representation of Unbalanced Linguistic Variables}

2.1.1. Unbalanced Linguistic Term Set. Suppose $S=\left\{s_{j} \mid\right.$ $j=0,1, \ldots, g-1\}$ is a finite and totally ordered discrete linguistic term set, where $s_{j}$ represent possible values for a 
linguistic variable and $g$ is an odd cardinality. Dong et al. [38] introduced the following combined definition for balanced and unbalanced linguistic term set.

Definition 1 (see [38]). Let $S=\left\{s_{0}, s_{1}, \ldots, s_{g-1}\right\}$ be a definite linguistic term set, $S_{C}$ be the midterm, and $N S: S \rightarrow R$ be a NS of $S . S$ is uniformly and symmetrically distributed if the following two conditions are satisfied: (1) There exists a unique constant $\lambda>0$ such that $N S\left(s_{i}\right)-N S\left(s_{j}\right)=l(i-j)$ for all $i, j=0,1, \ldots, g-1$; (2) let $S_{R}=\left\{s \mid s \in S, s>S_{C}\right\}$ and $S_{L}=\left\{s \mid s \in S, s<S_{C}\right\}$. Let $\mathbb{C}\left(S_{R}\right)$ and $\mathbb{C}\left(S_{L}\right)$ be the cardinality of $S_{R}$ and $S_{L}$; then $\mathbb{C}\left(S_{R}\right)=\mathbb{C}\left(S_{L}\right)$. If $S$ is uniformly and symmetrically distributed, then $S$ is called a balanced linguistic term set. Otherwise, $S$ is called an unbalanced linguistic term set.

2.1.2. 2-Tuple Fuzzy Linguistic Representation Model. The following 2-tuple fuzzy linguistic representation model extends traditional linguistic term set to a continuous case so as to facilitate computing with linguistic variables.

Definition 2 (see [18]). Let $S=\left\{s_{0}, s_{1}, \ldots, s_{g-1}\right\}$ be a linguistic term set, and $\beta \in[0, g]$. Then a 2-tuple fuzzy linguistic variable expresses the equivalent information to $\beta$ defined as

$$
\begin{aligned}
& \Delta:[0, g] \longrightarrow S \times[-0.5,0.5), \\
& \qquad(\beta)=\left(s_{i}, \alpha\right), \\
& \text { with } \begin{cases}s_{i}, & i=\operatorname{round}(\beta) \\
\alpha=\beta-i, & \alpha \in[-0.5,0.5),\end{cases} \\
& \Delta^{-1}\left(s_{i}, \alpha\right)=i+\alpha=\beta,
\end{aligned}
$$

where round $(\cdot)$ is the usual rounding operation and $\alpha$ is called symbolic translation.

2.1.3. Linguistic Hierarchies ( $L H$ ). To obtain 2-tuple fuzzy linguistic representations of unbalanced linguistic terms, the concept of linguistic hierarchies, that is, $\mathrm{LH}=\bigcup_{t} l(t, n(t))$, is used. $l(t, n(t))$ is a linguistic hierarchy with $t$ indicating the level of hierarchy and $n(t)$ denoting the granularity of the linguistic term set of $t$. Herrera et al. [18] defined the following transformation functions between labels from different levels in multigranular linguistic information contexts without loss of information.

Definition 3 (see [18]). In linguistic hierarchies LH = $\bigcup_{t} l(t, n(t))$ whose linguistic term sets are represented by $S^{n(t)}=\left\{s_{0}^{n(t)}, \ldots, s_{n(t)-1}^{n(t)}\right\}$, the transformation function from a linguistic label in level $t$ to a label in consecutive level $t^{\prime}$ is defined as $\mathrm{TF}_{t^{\prime}}^{t}: l(t, n(t)) \rightarrow l\left(t^{\prime}, n\left(t^{\prime}\right)\right)$ such that

$$
\begin{aligned}
& \mathrm{TF}_{t^{\prime}}^{t}\left(s_{i}^{n(t)}, \alpha^{n(t)}\right) \\
& \quad=\Delta_{t^{\prime}}\left(\frac{\Delta_{t}^{-1}\left(s_{i}^{n(t)}, \alpha^{n(t)}\right)\left(n\left(t^{\prime}\right)-1\right)}{n(t)-1}\right) .
\end{aligned}
$$

By use of the above transformation function, any 2tuple linguistic representation can be transformed into a term in LH. Detailed transformation procedures are listed in Appendix A.

2.2. Interval-Valued Dual Hesitant Fuzzy Set (IVDHFS). To manage those situations in which several values are possible for membership function of a fuzzy set, Torra [39] proposed the hesitant fuzzy set (HFS). Then, Zhu et al. [23] extend HFS to the dual hesitant fuzzy set by considering both crisp membership degrees and nonmembership degrees. However, precise degrees of an element to a set are often hard to specified. To overcome this barrier, Ju et al. [22] defined the interval-valued dual hesitant fuzzy set (IVDHFS).

Definition 4 (see [22]). Let $X$ be a fixed set; then an IVDHFS on $X$ is defined as

$$
\widetilde{D}=\{\langle x, \widetilde{h}(x), \widetilde{g}(x)\rangle \mid x \in X\},
$$

where $\widetilde{h}(x)=\bigcup_{\left[\mu^{L}, \mu^{U}\right] \in \tilde{h}(x)}\{\tilde{\mu}\}=\bigcup_{\left[\mu^{L}, \mu^{U}\right] \in \widetilde{h}(x)}\left\{\left[\mu^{L}, \mu^{U}\right]\right\}$ and $\tilde{g}(x)=\bigcup_{\left[v^{L}, v^{U}\right] \in \widetilde{g}(x)}\{\tilde{v}\}=\bigcup_{\left[\nu^{L}, v^{U}\right] \in \widetilde{g}(x)}\left\{\left[\nu^{L}, v^{U}\right]\right\}$ are two sets of interval values in $[0,1]$, denoting possible membership and nonmembership degrees of element $x \in X$ to the set $\widetilde{D}$, respectively, with conditions: $\tilde{\mu}, \widetilde{\nu} \in[0,1]$ and $0 \leq\left(\mu^{U}\right)^{+}+\left(\nu^{U}\right)^{+} \leq 1$ and, for all $x \in X,\left(\mu^{U}\right)^{+} \epsilon$ $\tilde{h}^{+}(x)=\bigcup_{\left[\mu^{L}, \mu^{U}\right] \in \tilde{h}(x)} \max \left\{\mu^{U}\right\}$, and $\left(\nu^{U}\right)^{+} \in \tilde{g}^{+}(x)=$ $\bigcup_{\left[\nu^{L}, \nu^{U}\right] \in \tilde{g}(x)} \max \left\{\nu^{U}\right\}$.

For convenience, normally $\widetilde{d}=\{\widetilde{h}, \widetilde{g}\}$ is called an intervalvalued dual hesitant fuzzy element (IVDHFE), and $\widetilde{D}$ is the set of all IVDHFEs.

\section{Interval-Valued Dual Hesitant Fuzzy Unbalanced Linguistic Set (IVDHFUBLS) and Its Aggregation Operators}

Practical applications have revealed objective necessity of the unbalanced linguistic term set (ULTS) [16-18]; in other words, ULTS intrinsically can meet the habits of human cognition and expression and can include traditional linguistic term sets as special cases, thus attaining better adaptability and flexibility. However, there is still a lack of study on hybrid expression tools based on ULTS for accommodating uncertain decision-making with decision hesitancy. Therefore, we here firstly define an effective expression tool of interval-valued dual hesitant fuzzy unbalanced linguistic set (IVDHFUBLS) and its fundamental operational rules; we next develop a distance measure for IVDHFUBLS that conquers potential information distortion in conventional methodology; then we develop some fundamental aggregation operators for IVDHFUBLS.

\subsection{Definition of IVDHFUBLS}

Definition 5. Let $X$ be a fixed set and $S$ be a finite and continuous linguistic label set; then an interval-valued dual 
hesitant fuzzy unbalanced linguistic set (IVDHFUBLS) $S D$ on $X$ is defined as

$$
S D=\left\{\left\langle x, s_{i}, \widetilde{h}(x), \widetilde{g}(x)\right\rangle \mid x \in X\right\},
$$

where $s_{i}$ is an unbalanced linguistic variable from predefined unbalanced linguistic label set $S$ which represents decisionmakers' judgements to an evaluated object $x ; \widetilde{h}(x)=$ $\bigcup_{\left[\mu^{L}, \mu^{U}\right] \in \tilde{h}(x)}\{\widetilde{\mu}\}=\bigcup_{\left[\mu^{L}, \mu^{U}\right] \in \tilde{h}(x)}\left\{\left[\mu^{L}, \mu^{U}\right]\right\}$ is a set of closed interval values in $[0,1]$, denoting possible membership degrees to which $x$ belongs to $s_{i}$; and $\widetilde{g}(x)=\bigcup_{\left[\nu^{L}, \nu^{U}\right] \in \widetilde{g}(x)}\{\widetilde{v}\}=$ $\bigcup_{\left[\nu^{L}, \nu^{U}\right] \in \tilde{g}(x)}\left\{\left[v^{L}, v^{U}\right]\right\}$ is a set of closed interval values in $[0,1]$, denoting possible nonmembership degrees to which $x$ belongs to $s_{i}$. In $\widetilde{h}(x)$ and $\widetilde{g}(x), \widetilde{\mu}, \widetilde{v} \in[0,1]$ and $0 \leq\left(\mu^{U}\right)^{+}+$ $\left(\nu^{U}\right)^{+} \leq 1$, where $\left(\mu^{U}\right)^{+} \in \widetilde{h}^{+}(x)=\bigcup_{\left[\mu^{L}, \mu^{U}\right] \in \widetilde{h}(x)} \max \left\{\mu^{U}\right\}$ and $\left(\nu^{U}\right)^{+} \in \widetilde{g}^{+}(x)=\bigcup_{\left[\nu^{L}, \nu^{U}\right] \in \tilde{g}(x)} \max \left\{\nu^{U}\right\}$ for all $x \in X$.

For convenience, $s d=\left(s_{i}, \widetilde{h}, \widetilde{g}\right)$ is called an intervalvalued dual hesitant fuzzy unbalanced linguistic number (IVDHFUBLN).

\subsection{Operational Rules for IVDHFUBLS}

Definition 6. Let $s d=\left(s_{k}, \widetilde{h}, \widetilde{g}\right), s d_{1}=\left(s_{i}, \widetilde{h}_{1}, \widetilde{g}_{1}\right)$, and $s d_{2}=$ $\left(s_{j}, \widetilde{h}_{2}, \widetilde{g}_{2}\right)$ be any three IVDHFUBLNs, $\lambda \in[0,1]$; some operations on these IVDHFUBLNs are defined by

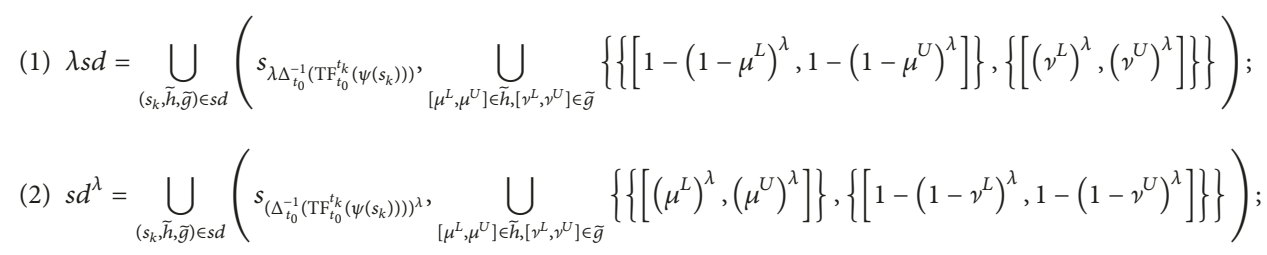

(3) $s d_{1} \oplus s d_{2}$

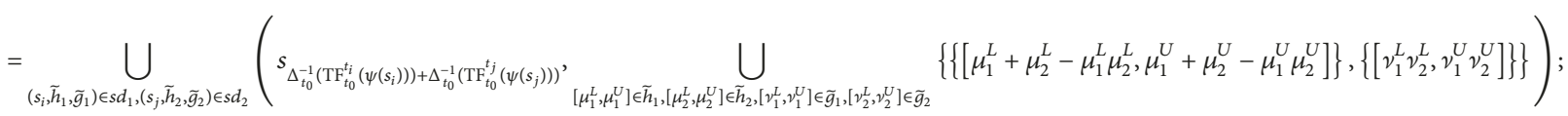

(4) $s d_{1} \otimes s d_{2}$

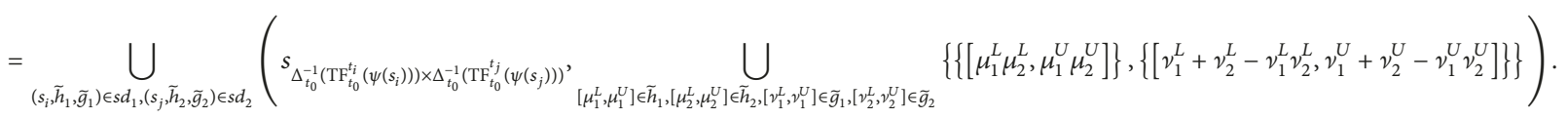

Theorem 7. Let $s d=\left(s_{k}, \widetilde{h}, \widetilde{g}\right), s d_{1}=\left(s_{i}, \widetilde{h}_{1}, \widetilde{g}_{1}\right)$, and $s d_{2}=$ $\left(s_{j}, \widetilde{h}_{2}, \widetilde{g}_{2}\right)$ be any three IVDHFUBLNs; then the following properties are true:

(1) $s d_{1} \oplus s d_{2}=s d_{2} \oplus s d_{1}$.

(2) $s d_{1} \otimes s d_{2}=s d_{2} \otimes s d_{1}$.

(3) $\lambda\left(s d_{1} \oplus s d_{2}\right)=\lambda s d_{1} \oplus \lambda s d_{2}, \lambda \in[0,1]$.

(4) $s d_{1}^{\lambda} \otimes s d_{2}^{\lambda}=\left(s d_{1} \otimes s d_{2}\right)^{\lambda}, \lambda \in[0,1]$.

(5) $\lambda_{1} s d \oplus \lambda_{2} s d=\left(\lambda_{1}+\lambda_{2}\right) s d, \lambda_{1}, \lambda_{2} \in[0,1]$.

(6) $s d^{\lambda_{1}} \otimes s d^{\lambda_{2}}=s d^{\lambda_{1}+\lambda_{2}}, \lambda_{1}, \lambda_{2} \in[0,1]$.

Proof. See Appendix B.

In Definition 6 and Theorem $7, t_{k}, t_{i}, t_{j}$ are corresponding levels of $s_{k}, s_{i}, s_{j}$ in LH, respectively. $t_{0}$ is the maximum level of $s_{k}, s_{i}, s_{j}$ in LH.

In order to compare two IVDHFUBLNs, we define the following score function and accuracy function, based on which a comparison method for two IVDHFUBLNs is presented.
Definition 8. Let $s d=\left(s_{i}, \widetilde{h}, \widetilde{g}\right)$ be an IVDHFUBLN; then score function $S(s d)$ can be represented by

$$
\begin{aligned}
& S(s d)=\Delta_{t_{0}}^{-1}\left(\operatorname{TF}_{t_{0}}^{t_{i}}\left(\psi\left(s_{i}\right)\right)\right) \times \frac{1}{2}\left(\frac{1}{l(\widetilde{h})_{\left[\mu^{L}, \mu^{U}\right] \in \tilde{h}}} \sum^{L}\right. \\
& -\frac{1}{l(\widetilde{g})} \sum_{\left[\nu^{L}, \nu^{U}\right] \in \widetilde{g}} \nu^{L}+\frac{1}{l(\widetilde{h})} \sum_{\left[\mu^{L}, \mu^{U}\right] \in \widetilde{h}} \mu^{U} \\
& \left.-\frac{1}{l(\widetilde{g})} \sum_{\left[\nu^{L}, \nu^{U}\right] \in \tilde{g}} \nu^{U}\right)
\end{aligned}
$$

where $l(\widetilde{h})$ and $l(\widetilde{g})$ are numbers of interval values in $\widetilde{h}$ and $\widetilde{g}$, respectively, $t_{i}$ is the corresponding level of $s_{i}$ in $\mathrm{LH}$, and $t_{0}$ is the maximum level of $t_{i}$ in LH.

Definition 9. Let $s d=\left(s_{i}, \widetilde{h}, \widetilde{g}\right)$ be an IVDHFUBLN; then accuracy function $P(s d)$ can be represented by

$$
P(s d)=\Delta_{t_{0}}^{-1}\left(\operatorname{TF}_{t_{0}}^{t_{i}}\left(\psi\left(s_{i}\right)\right)\right) \times \frac{1}{2}\left(\frac{1}{l(\widetilde{h})} \sum_{\left[\mu^{L}, \mu^{U}\right] \in \widetilde{h}} \mu^{L}\right.
$$




$$
\begin{aligned}
& +\frac{1}{l(\widetilde{g})} \sum_{\left[\nu^{L}, \nu^{U}\right] \in \tilde{g}} \nu^{L}+\frac{1}{l(\widetilde{h})} \sum_{\left[\mu^{L}, \mu^{U}\right] \in \tilde{h}} \mu^{U} \\
& \left.+\frac{1}{l(\widetilde{g})} \sum_{\left[\nu^{L}, \nu^{U}\right] \in \widetilde{g}} \nu^{U}\right)
\end{aligned}
$$

where $l(\widetilde{h})$ and $l(\widetilde{g})$ are numbers of interval values in $\widetilde{h}$ and $\widetilde{g}$, respectively, $t_{i}$ is the corresponding level of $s_{i}$ in the $\mathrm{LH}$, and $t_{0}$ is the maximum level of $t_{i}$ in $\mathrm{LH}$.

Definition 10. Given any two IVDHFUBLNs $s d_{1}=\left(s_{i}, \widetilde{h}_{1}, \widetilde{g}_{1}\right)$ and $s d_{2}=\left(s_{j}, \widetilde{h}_{2}, \widetilde{g}_{2}\right)$, then based on the former score function and accuracy function, we have the following:

(1) If $S\left(s d_{1}\right)<S\left(s d_{2}\right)$, then $s d_{1}<s d_{2}$.

(2) If $S\left(s d_{1}\right)=S\left(s d_{2}\right)$, then

(a) if $P\left(s d_{1}\right)=P\left(s d_{2}\right)$, then $s d_{1}=s d_{2}$;

(b) if $P\left(s d_{1}\right)<P\left(s d_{2}\right)$, then $s d_{1}<s d_{2}$.

3.3. Proposed Distance Measure for IVDHFUBLS. When measuring distances between two hesitant fuzzy numbers, appropriate strategies should be determined for handling unequal lengths of membership set or nonmembership set [37]. Generally, the complementing strategies have been widely adopted [36,37], which appends more elements to the membership set or nonmembership set with shorter length till matching. However, the complementing methods hold their own circumscribed perspectives and thus will potentially bring about information distortion to some extent. In order to avoid the potential information distortion, we here define a novel distance measure for IVDHFUBLS, which as shown in the following Definition 11 manages to bypass the artificial filling process and objectively compute distance among two numbers in the form of IVDHFUBLS.

Definition 11. Let two IVDHFUBLNs $s d_{1}=\left(s_{i}, \widetilde{h}_{1}, \widetilde{g}_{1}\right)$ and $s d_{2}=\left(s_{j}, \widetilde{h}_{2}, \widetilde{g}_{2}\right) ; l_{\tilde{h}_{1}}, l_{\tilde{h}_{2}}, l_{\widetilde{g}_{1}}$, and $l_{\widetilde{g}_{2}}$ are the lengths of $\widetilde{h}_{1}, \widetilde{h}_{2}$, $\widetilde{g}_{1}$, and $\widetilde{g}_{2}$, respectively, which represent number of elements in the sets of $\widetilde{h}_{1}, \widetilde{h}_{2}, \widetilde{g}_{1}$, and $\widetilde{g}_{2}$. Suppose $I_{1}=\left(1 /\left(n\left(t_{i}\right)-\right.\right.$ 1)) $\Delta_{t_{0}}^{-1}\left(\mathrm{TF}_{t_{0}}^{t_{i}}\left(\psi\left(s_{i}\right)\right)\right)$ and $I_{2}=\left(1 /\left(n\left(t_{j}\right)-1\right)\right) \Delta_{t_{0}}^{-1}\left(\operatorname{TF}_{t_{0}}^{t_{j}}\left(\psi\left(s_{j}\right)\right)\right)$, where $t_{i}$ and $t_{j}$ are the corresponding levels of unbalanced linguistic terms $s_{i}$ and $s_{j}$ in the linguistic hierarchy LH and $t_{0}$ is the maximum level of $s_{i}$ and $s_{j}$ in LH. Then based on the widely adopted normalized Euclidean distance, we define a distance measure $d$ for IVDHFUBLNs as follows.

Situation 1. When $l_{\widetilde{h}_{1}}=l_{\widetilde{h}_{2}}=l_{1}$ and $l_{\widetilde{g}_{1}}=l_{\widetilde{g}_{2}}=l_{2}$, then

$$
\begin{aligned}
& d\left(s d_{1}, s d_{2}\right)=\left(\frac { 1 } { 2 } \left(\frac{1}{l_{1}}\right.\right. \\
& \quad \cdot \sum_{k=1}^{l_{1}}\left(\left|I_{1} \mu_{h_{1}}^{L_{j}}-I_{2} \mu_{h_{2}}^{L_{k}}\right|^{2}+\left|I_{1} \mu_{h_{1}}^{U_{j}}-I_{2} \mu_{h_{2}}^{U_{k}}\right|^{2}\right)+\frac{1}{l_{2}}
\end{aligned}
$$

$$
\left.\left.\cdot \sum_{k=1}^{l_{2}}\left(\left|I_{1} \nu_{\widetilde{g}_{1}}^{L_{j}}-I_{2} \nu_{\widetilde{g}_{2}}^{L_{k}}\right|^{2}+\left|I_{1} \nu_{\widetilde{g}_{1}}^{U_{j}}-I_{2} \nu_{\tilde{g}_{2}}^{U_{k}}\right|^{2}\right)\right)\right)^{1 / 2}
$$

Situation 2. When $l_{\widetilde{h}_{1}} \neq l_{\widetilde{h}_{2}}$ or $l_{\widetilde{g}_{1}} \neq l_{\widetilde{g}_{2}}$, then

$$
\begin{aligned}
& d\left(s d_{1}, s d_{2}\right)=\left(\frac { 1 } { 2 } \left(\frac{1}{l_{\widetilde{h}_{1}} l_{\widetilde{h}_{2}}}\right.\right. \\
& \cdot \sum_{j=1}^{h_{\tilde{h}_{1}}} \sum_{k=1}^{h_{\tilde{h}_{2}}}\left(\left|I_{1} \mu_{\hat{h}_{1}}^{L_{j}}-I_{2} \mu_{\hat{h}_{2}}^{L_{k}}\right|^{2}+\left|I_{1} \mu_{\tilde{h}_{1}}^{U_{j}}-I_{2} \mu_{\hat{h}_{2}}^{U_{k}}\right|^{2}\right) \\
& +\frac{1}{l_{\widetilde{g}_{1}} l_{\widetilde{g}_{2}}} \\
& \left.\cdot \sum_{j=1}^{l_{\tilde{g}_{1}}} \sum_{k=1}^{l_{\tilde{g}_{2}}}\left(\left|I_{1} \nu_{\widetilde{g}_{1}}^{L_{j}}-I_{2} \nu_{\tilde{g}_{2}}^{L_{k}}\right|^{2}+\left|I_{1} v_{\widetilde{g}_{1}}^{U_{j}}-I_{2} \nu_{\tilde{g}_{2}}^{U_{k}}\right|^{2}\right)\right)^{1 / 2} .
\end{aligned}
$$

Theorem 12. The distance measure for IVDHFUBLNs $d$ also satisfies the following properties:

(1) $0 \leq d\left(s d_{1}, s d_{2}\right) \leq 1$.

(2) $d\left(s d_{1}, s d_{2}\right)=0$ if and only if $I_{1}=I_{2}, \widetilde{h}_{1}=\widetilde{h}_{2}$, and $\widetilde{g}_{1}=\widetilde{g}_{2}$.

(3) $d\left(s d_{1}, s d_{2}\right)=d\left(s d_{2}, s d_{1}\right)$.

Definition 13. Given two IVDHFUBLNs, $s d_{1}=\left(s_{i}, \widetilde{h}_{1}, \widetilde{g}_{1}\right)$ and $s d_{2}=\left(s_{j}, \widetilde{h}_{2}, \widetilde{g}_{2}\right)$, when $s_{i}$ and $s_{j}$ happen to be from two balanced linguistic term sets in LH but with different linguistic granularities, $I_{1}$ and $I_{2}$ should be calculated according to

$$
\begin{aligned}
& I_{1}=\frac{1}{n\left(t_{i}\right)-1} \Delta_{t_{0}}^{-1}\left(\mathrm{TF}_{t_{0}}^{t_{i}}\left(s_{i}\right)\right), \\
& I_{2}=\frac{1}{n\left(t_{j}\right)-1} \Delta_{t_{0}}^{-1}\left(\mathrm{TF}_{t_{0}}^{t_{j}}\left(s_{j}\right)\right) .
\end{aligned}
$$

Then for this type of cases, based on the normalized Euclidean distance and (12), the distance measure $d$ for IVDHFUBLNs can be written as the same Situations 1 and 2 in Definition 11.

3.4. Proposed Aggregation Operators for IVDHFUBLS. In this section, based on the above-proposed distance measures, we develop some fundamental aggregation operators for IVDHFUBLS.

\subsubsection{Weighted Interval-Valued Dual Hesitant Fuzzy Unbalanced Linguistic Power Aggregation Operator}

Definition 14. For a collection of IVDHFUBLNs $s d_{j}(j=$ $1,2, \ldots, n)$, a weighted interval-valued dual hesitant fuzzy 
unbalanced linguistic power average (W-IVDHFUBL-PA) operator is a mapping $S^{n} \rightarrow S$ :

$$
\begin{gathered}
\text { W-IVDHFUBL-PA } A_{\omega}\left(s d_{1}, s d_{2}, \ldots, s d_{n}\right) \\
=\frac{\bigoplus_{j=1}^{n}\left(\omega_{j}\left(1+T\left(s d_{j}\right)\right) s d_{j}\right)}{\sum_{i=1}^{n} \omega_{i}\left(1+T\left(s d_{i}\right)\right)}
\end{gathered}
$$

where

$$
T\left(s d_{j}\right)=\sum_{k=1, k \neq j}^{n} \omega_{k} \sup \left(s d_{j}, s d_{k}\right)
$$

$\omega=\left(\omega_{1}, \omega_{2}, \ldots, \omega_{n}\right)^{T}$ is the weighting vector for $s d_{j}$ with $\omega_{j} \in$ $[0,1]$ and $\sum_{j=1}^{n} \omega_{j}=1 . \sup \left(s d_{j}, s d_{k}\right)$ is the support degrees for $s d_{j}$ from $s d_{k}$, which satisfy the following three properties:

(1) $\sup \left(s d_{j}, s d_{k}\right) \in[0,1]$.

(2) $\sup \left(s d_{j}, s d_{k}\right)=\sup \left(s d_{k}, s d_{j}\right)$.

(3) $\sup \left(s d_{j}, s d_{k}\right) \geq \sup \left(s d_{i}, s d_{s}\right)$, if $d\left(s d_{j}, s d_{k}\right)<$ $d\left(s d_{i}, s d_{s}\right)$, where $d$ is the distance measure between two IVDHFUBLNs.

Theorem 15. Let $s d_{j}=\left(s_{j}, \widetilde{h}_{j}, \widetilde{g}_{j}\right)$ be a collection of IVDHFUBLNs; then aggregation results by Definition 14 are transformed to the form of interval-valued dual hesitant fuzzy balanced linguistic (IVDHFBL) variables, and

$$
\begin{aligned}
& \text { W-IVDHFUBL-PA }\left(s d_{1}, s d_{2}, \ldots, s d_{n}\right) \\
& =\bigcup_{\left(s_{j}, \widetilde{h}_{j}, \tilde{g}_{j}\right) \in s d_{j}}\left(s_{\sum_{j=1}^{n}\left(\omega_{j}\left(1+T\left(s d_{j}\right)\right) / \sum_{i=1}^{n} \omega_{j}\left(1+T\left(s d_{i}\right)\right)\right) \Delta_{t_{0}}^{-1}\left(T F_{t_{0}}^{t_{j}}\left(\psi\left(s_{j}\right)\right)\right)},\right. \\
& \bigcup_{\left[\mu_{j}^{L}, \mu_{j}^{U}\right] \in \widetilde{h}_{j},\left[\nu_{j}^{L}, \nu_{j}^{U}\right] \in \widetilde{g}_{j}}\left\{\left\{\left[1-\prod_{j=1}^{n}\left(1-\mu_{j}^{L}\right)^{\omega_{j}\left(1+T\left(s d_{j}\right)\right) / \sum_{i=1}^{n} \omega_{j}\left(1+T\left(s d_{i}\right)\right),},\right.\right.\right. \\
& \left.\left.1-\prod_{j=1}^{n}\left(1-\mu_{j}^{U}\right)^{\omega_{j}\left(1+T\left(s d_{j}\right)\right) / \sum_{i=1}^{n} \omega_{j}\left(1+T\left(s d_{i}\right)\right)}\right]\right\}, \\
& \left\{\left[\prod_{j=1}^{n}\left(v_{j}^{L}\right)^{\omega_{j}\left(1+T\left(s d_{j}\right)\right) / \sum_{i=1}^{n} \omega_{j}\left(1+T\left(s d_{i}\right)\right)},\right.\right. \\
& \left.\left.\left.\left.\prod_{j=1}^{n}\left(\nu_{j}^{U}\right)^{\omega_{j}\left(1+T\left(s d_{j}\right)\right) / \sum_{i=1}^{n} \omega_{j}\left(1+T\left(s d_{i}\right)\right)}\right]\right\}\right\}\right),
\end{aligned}
$$

where $\omega=\left(\omega_{1}, \omega_{2}, \ldots, \omega_{n}\right)^{T}$ is the weight vector of $s d_{j}$ with $\omega_{j} \in[0,1]$ and $\sum_{j=1}^{n} \omega_{j}=1$.

Proof. See Appendix C.

Theorem 16. The W-IVDHFUBL-PA operator holds the following properties:

(1) Idempotency: let $s d_{j}=s d$, for all $j=1,2, \ldots, n$; then

$$
W-I V D H F U B L-P A\left(s d_{1}, s d_{2}, \ldots, s d_{n}\right)=s d
$$

(2) Bounded: the W-IVDHFUBL-PA operator lies between the max and min operators:

$s d^{-} \leq W-I V D H F U B L-P A\left(s d_{1}, s d_{2}, \ldots, s d_{n}\right) \leq s d^{+}$.

Proof. See Appendix D.

\subsubsection{Interval-Valued Dual Hesitant Fuzzy Unbalanced Linguistic Power Aggregation Operator}

Definition 17. For a collection of IVDHFUBLNs $s d_{j}(j=$ $1,2, \ldots, n)$, an interval-valued dual hesitant fuzzy unbalanced linguistic power average (IVDHFUBL-PA) operator is a mapping $S^{n} \rightarrow S:$

$$
\begin{gathered}
\operatorname{IVDHFUBL-PA}\left(s d_{1}, s d_{2}, \ldots, s d_{n}\right) \\
=\frac{\bigoplus_{j=1}^{n}\left(1+T\left(s d_{j}\right)\right) s d_{j}}{\sum_{i=1}^{n}\left(1+T\left(s d_{i}\right)\right)}
\end{gathered}
$$

where

$$
T\left(s d_{j}\right)=\sum_{k=1, k \neq j}^{n} \sup \left(s d_{j}, s d_{k}\right) .
$$

$\sup \left(s d_{j}, s d_{k}\right)$ is the support degrees of $s d_{j}$ from $s d_{k}$.

Theorem 18. Let $s d_{j}=\left(s_{j}, \tilde{h}_{j}, \tilde{g}_{j}\right)$ be a collection of IVDHFUBLNs; then aggregation results from Definition 17 are transformed to the form of IVDHFBL variables, and

$$
\begin{aligned}
& \operatorname{IVDHFUBL-PA}\left(s d_{1}, s d_{2}, \ldots, s d_{n}\right) \\
& =\bigcup_{\left(s_{j}, \widetilde{h}_{j}, \widetilde{g}_{j}\right) \in s d_{j}}\left(s_{\sum_{j=1}^{n}\left(\left(1+T\left(s d_{j}\right)\right) / \sum_{i=1}^{n}\left(1+T\left(s d_{i}\right)\right)\right) \Delta_{t_{0}}^{-1}\left(T F_{t_{0}}^{t_{j}}\left(\psi\left(s_{j}\right)\right)\right)},\right. \\
& \bigcup_{\left[\mu_{j}^{L}, \mu_{j}^{U}\right] \in \widetilde{h}_{j},\left[\nu_{j}^{L}, v_{j}^{U}\right] \in \widetilde{g}_{j}}\left\{\left\{\left[1-\prod_{j=1}^{n}\left(1-\mu_{j}^{L}\right)^{\left(1+T\left(s d_{j}\right)\right) / \sum_{i=1}^{n}\left(1+T\left(s d_{i}\right)\right)},\right.\right.\right. \\
& \left.\left.1-\prod_{j=1}^{n}\left(1-\mu_{j}^{U}\right)^{\left(1+T\left(s d_{j}\right)\right) / \sum_{i=1}^{n}\left(1+T\left(s d_{i}\right)\right)}\right]\right\}, \\
& \left\{\left[\prod_{j=1}^{n}\left(v_{j}^{L}\right)^{\left(1+T\left(s d_{j}\right)\right) / \sum_{i=1}^{n}\left(1+T\left(s d_{i}\right)\right)},\right.\right. \\
& \left.\left.\left.\left.\prod_{j=1}^{n}\left(\nu_{j}^{U}\right)^{\left(1+T\left(s d_{j}\right)\right) / \sum_{i=1}^{n}\left(1+T\left(s d_{i}\right)\right)}\right]\right\}\right\}\right) .
\end{aligned}
$$

Proof. It is omitted here for conciseness.

Theorem 19. IVDHFUBL-PA operator holds following properties:

(1) Commutativity: let $\left(s d_{1}{ }^{*}, s d_{2}{ }^{*}, \ldots, s d_{n}{ }^{*}\right)$ be any permutation of $\left(s d_{1}, s d_{2}, \ldots, s d_{n}\right)$; then 


$$
\begin{aligned}
& \operatorname{IVDHFUBL-PA}\left(s d_{1}{ }^{*}, s d_{2}{ }^{*}, \ldots, s d_{n}{ }^{*}\right) \\
& \quad=\operatorname{IVDHFUBL-PA}\left(s d_{1}, s d_{2}, \ldots, s d_{n}\right) .
\end{aligned}
$$

(2) Idempotency: let $s d_{j}=s d$, for all $j=1,2, \ldots, n$; then

$$
\operatorname{IVDHFUBL-PA}\left(s d_{1}, s d_{2}, \ldots, s d_{n}\right)=s d .
$$

Proof. See Appendix E.
Theorem 20. For a collection of IVDHFUBLNs $s d_{j}=\left(s_{j}, \widetilde{h}_{j}\right.$, $\left.\tilde{g}_{j}\right)$, if $\omega=(1 / n, 1 / n, \ldots, 1 / n)^{T}$, then the W-IVDHFUBL-PA operator reduces to the IVDHFUBL-PA operator.

Theorem 21. For a collection of IVDHFUBLNs $s d_{j}=$ $\left(s_{j}, \widetilde{h}_{j}, \widetilde{g}_{j}\right)$, if $\sup \left(s d_{i}, s d_{j}\right)=k$ for all $i \neq j$, then the IVDHFUBL-PA operator reduces to the interval-valued dual hesitant fuzzy unbalanced linguistic average (IVDHFUBLA) operator:

$$
\begin{aligned}
& \operatorname{IVDhFubLA}\left(s d_{1}, s d_{2}, \ldots, s d_{n}\right)=\bigcup_{\left(s_{j}, \widetilde{h}_{j}, \tilde{g}_{j}\right) \in s d_{j}}\left(s_{(1 / n) \sum_{j=1}^{n} \Delta_{t_{0}}^{-1}\left(T t_{t_{0}}^{t_{j}}\left(\psi\left(s_{j}\right)\right)\right)^{\prime}}\right. \\
& \left.\underset{\left[\mu_{j}^{L}, \mu_{j}^{U}\right] \in \widetilde{h}_{j},\left[v_{j}^{L}, v_{j}^{U}\right] \in \widetilde{g}_{j}}{ }\left\{\left\{\left[1-\prod_{j=1}^{n}\left(1-\mu_{j}^{L}\right)^{1 / n}, 1-\prod_{j=1}^{n}\left(1-\mu_{j}^{U}\right)^{1 / n}\right]\right\},\left\{\left[\prod_{j=1}^{n}\left(v_{j}^{L}\right)^{1 / n}, \prod_{j=1}^{n}\left(\nu_{j}^{U}\right)^{1 / n}\right]\right\}\right\}\right) .
\end{aligned}
$$

Theorem 22. For a collection of IVDHFUBLNs $s d_{j}=$ $\left(s_{j}, \widetilde{h}_{j}, \widetilde{g}_{j}\right)$, if $s_{j}$ in sd $d_{j}$ reduces to the form of balanced linguistic variable, $s d_{j}(j=1,2, \ldots, n)$ reduces to a collection of intervalvalue dual hesitant fuzzy balanced linguistic numbers (IVDHFBLNs) $\overline{s d}_{j}(j=1,2, \ldots, n)$. Suppose $\overline{s d}_{j}(j=1,2, \ldots, n)$ have different linguistic granularities; then the IVDHFUBL$P A$ reduces to the following interval-valued dual hesitant fuzzy linguistic power average (IVDHFL-PA) operator:

$$
\begin{aligned}
& \text { IVDHFL-PA }\left(\overline{s d}_{1}, \overline{s d}_{2}, \ldots, \overline{s d}_{n}\right) \\
& =\bigcup_{\left(s_{j}, \tilde{h}_{j}, \tilde{g}_{j}\right) \in \overline{s d_{j}}}\left(s_{\sum_{j=1}^{n}\left(\left(1+T\left(\overline{s d_{j}}\right)\right) / \sum_{i=1}^{n}\left(1+T\left(\overline{s_{i}}\right)\right)\right) \Delta_{t_{0}^{-1}}^{-1}\left(T F_{t_{0}}^{t_{j}}\left(s_{j}\right)\right)},\right. \\
& \bigcup_{\left[\mu_{j}^{L}, \mu_{j}^{U}\right] \in \bar{h}_{j},\left[\nu_{j}^{L}, \nu_{j}^{U}\right] \in \tilde{g}_{j}}\left\{\left\{\left[1-\prod_{j=1}^{n}\left(1-\mu_{j}^{L}\right)^{\left(1+T\left(\overline{s d_{j}}\right)\right) / \sum_{i=1}^{n}\left(1+T\left(\overline{s d_{i}}\right)\right)},\right.\right.\right. \\
& \left.\left.1-\prod_{j=1}^{n}\left(1-\mu_{j}^{U}\right)^{\left(1+T\left(\overline{s d_{j}}\right)\right) / \sum_{i=1}^{n}\left(1+T\left(\bar{s} \bar{d}_{i}\right)\right)}\right]\right\}, \\
& \left\{\left[\prod_{j=1}^{n}\left(v_{j}^{L}\right)^{\left(1+T\left(s d_{j}\right) \overline{s d_{j}}\right) / \sum_{i=1}^{n}\left(1+T\left(\bar{s} \bar{d}_{i}\right)\right)},\right.\right. \\
& \left.\left.\left.\left.\prod_{j=1}^{n}\left(v_{j}^{U}\right)^{\left(1+T\left(\overline{s d_{j}}\right)\right) / \sum_{i=1}^{n}\left(1+T\left(\bar{s} \bar{d}_{i}\right)\right)}\right]\right\}\right\}\right) \text {. }
\end{aligned}
$$

\subsubsection{Induced Interval-Valued Dual Hesitant Fuzzy Unbalanced Linguistic Power Ordered Weighted Aggregation Operators}

Definition 23. For a collection of IVDHFUBLNs $s d_{j}$, an induced interval-valued dual hesitant fuzzy unbalanced linguistic power ordered weighted average (I-IVDHFUBLPOWA) operator can be defined as a mapping $S^{n} \rightarrow$ $S$ :

$$
\begin{aligned}
& \operatorname{I-IVDHFUBL-POWA}\left(\left\langle u_{1}, s d_{1}\right\rangle,\left\langle u_{2}, s d_{2}\right\rangle, \ldots,\right. \\
& \left.\left\langle u_{n}, s d_{n}\right\rangle\right)=\bigoplus_{j=1}^{n}\left(w_{j} s d_{\sigma(j)}\right)
\end{aligned}
$$

where $s d_{\sigma(j)}$ is the $j$ th largest or smallest of them, $u_{i}$ in $\left\langle u_{i}, s d_{i}\right\rangle$ is referred to as the order-inducing vector $u=$ $\left(u_{1}, u_{2}, \ldots, u_{n}\right)$ that can be determined by decision-makers' expertise attitudes, and $w_{j}=g\left(R_{j} / T V\right)-g\left(R_{j-1} / T V\right)$ is constrained by $w_{j} \in[0,1]$ and $\sum_{j=1}^{n} w_{j}=1, R_{j}=\sum_{k=1}^{j} V_{\sigma(k)}$, $T V=\sum_{j=1}^{n} V_{\sigma(j)}$, where

$$
\begin{aligned}
V_{\sigma(j)} & =1+T\left(s d_{\sigma(j)}\right), \\
T\left(s d_{\sigma(j)}\right) & =\sum_{k=1, k \neq j}^{n} \sup \left(s d_{\sigma(j)}, s d_{\sigma(k)}\right) .
\end{aligned}
$$

In (26), $T\left(s d_{\sigma(j)}\right)$ denotes support of $j$ th largest or smallest argument by all the other arguments, and $\sup \left(s d_{\sigma(j)}, s d_{\sigma(k)}\right)$ indicates support for $s d_{\sigma(j)}$ from $s d_{\sigma(k)}$. $g:[0,1] \rightarrow[0,1]$ is a basic unit interval monotonic (BUM) function which satisfies $g(0)=0, g(1)=1$, and $g(x) \geq g(y)$ if $x>y$.

Theorem 24. Let $s d_{j}=\left(s_{j}, \widetilde{h}_{j}, \widetilde{g}_{j}\right)$ be a collection of IVDHFUBLNs; aggregation results from Definition 23 are transformed to the form of interval-valued dual hesitant fuzzy balanced linguistic variables, and 


$$
\begin{aligned}
& \operatorname{I-IVDHFUBL-POWA}\left(s d_{1}, s d_{2}, \ldots, s d_{n}\right)=\underset{\left(s_{\sigma(j)}, \tilde{h}_{\sigma(j)}, \tilde{g}_{\sigma(j)}\right) \in s d_{\sigma(j)}}{ }\left(s_{\sum_{j=1}^{n} w_{j} \Delta_{t_{0}}^{-1}\left(T F_{t_{0}}^{t_{j}}\left(\psi\left(s_{\sigma(j)}\right)\right)\right)},\right. \\
& \left.\bigcup_{\left[\mu_{\sigma(j)}^{L}, \mu_{\sigma(j)}^{U}\right] \in \tilde{h}_{\sigma(j)},\left[\nu_{\sigma(j)}^{L}, v_{\sigma(j)}^{U}\right] \in \tilde{g}_{\sigma(j)}}\left\{\left\{\left[1-\prod_{j=1}^{n}\left(1-\mu_{\sigma(j)}^{L}\right)^{w_{j}}, 1-\prod_{j=1}^{n}\left(1-\mu_{\sigma(j)}^{U}\right)^{w_{j}}\right]\right\},\left\{\left[\prod_{j=1}^{n}\left(v_{\sigma(j)}^{L}\right)^{w_{j}}, \prod_{j=1}^{n}\left(\nu_{\sigma(j)}^{U}\right)^{w_{j}}\right]\right\}\right\}\right),
\end{aligned}
$$

where $w_{j}$ satisfies (26) and $s d_{\sigma(j)}=\left(s_{\sigma(j)}, \tilde{h}_{\sigma(j)}, \widetilde{g}_{\sigma(j)}\right)$ is the $j$ th largest or smallest of $s d_{j}(j=1,2, \ldots, n)$ reordered according to the order-inducing variable $u_{j}$.

Proof. It is omitted for conciseness.

Theorem 25. For a collection of IVDHFUBLNs $s d_{j}=$ $\left(s_{j}, \tilde{h}_{j}, \tilde{g}_{j}\right)$, if $w=(1 / n, 1 / n, \ldots, 1 / n)^{T}$, then I-IVDHFUBLPOWA operator reduces to the interval-valued dual hesitant fuzzy unbalanced linguistic average (IVDHFUBLA) operator described in Theorem 21.

\section{MAGDM Approaches Based on IVDHFUBLS and Numerical Studies}

4.1. Approaches for MAGDM under Interval-Valued Dual Hesitant Fuzzy Unbalanced Linguistic Environments. In this section, we apply the afore-developed aggregation operators to construct effective approaches for MAGDM under interval-valued dual hesitant fuzzy unbalanced linguistic environments.

Let $A=\left\{A_{1}, A_{2}, \ldots, A_{m}\right\}$ be a set of alternatives and $C=$ $\left\{C_{1}, C_{2}, \ldots, C_{n}\right\}$ be a set of attributes. $\omega=\left(\omega_{1}, \omega_{2}, \ldots, \omega_{n}\right)^{T}$ denotes the weighting vector for attribute vector $C$, where, for all $i=1,2, \ldots, n, \omega_{i} \geq 0$ and $\sum_{i=1}^{n} \omega_{i}=1 . D=\left\{d_{1}, d_{2}, \ldots, d_{t}\right\}$ represents a set of decision-makers and $\eta=\left(\eta_{1}, \eta_{2}, \ldots, \eta_{t}\right)$ is the weighting vector for experts in $D$, with $\eta_{k} \geq 0(k=$ $1,2, \ldots, t)$ and $\sum_{k=1}^{t} \eta_{k}=1$. Suppose that $R^{k}=\left(r_{i j}^{k}\right)_{n \times m}$ is the decision matrix given by decision-maker $d_{k}$ based on an unbalanced linguistic term set $S^{k}$ regarding alternative $A_{j}$ under attribute $C_{i}$, where $r_{i j}^{k}=\left(s_{\alpha_{i j}}^{k}, \widetilde{h}_{i j}^{k}, \tilde{g}_{i j}^{k}\right), s_{\alpha_{i j}}^{k} \in S^{k}$, takes the form of interval-valued dual hesitant fuzzy unbalanced linguistic numbers (IVDHFUBLNs).

Now, according to specific complex scenarios whether comprising attributes weights, experts weights, and additional expertise attitudes or not, we construct two effective MAGDM approaches based on the above-developed power aggregation operators to accommodate Cases 1 and 2, respectively.

Case 1. Considering that weighting vectors for both decisionmakers and attributes are known in advance, we apply the W-IVDHFUBL-PA operator denoted in Definition 14 to structure Approach 1 for multiple attributes group decision-making under interval-valued dual hesitant fuzzy unbalanced linguistic environment.

Approach 1. The first approach is MAGDM based on IVDHFUBLS: with known weighting information for both expert weights and attribute weights.

Step 1.1. Calculate support degrees of attribute values in each individual decision matrix. Here, taking the decision matrix $R^{k}=\left(r_{i j}^{k}\right)_{n \times m}$ by the $k$ th decision-maker as example, the support degrees $\sup \left(r_{i j}^{k}, r_{p j}^{k}\right)$ can be computed according to

$$
\begin{aligned}
& \sup \left(r_{i j}^{k}, r_{p j}^{k}\right)=1-d\left(r_{i j}^{k}, r_{p j}^{k}\right), \\
& i, p=1,2, \ldots, n ; j=1,2, \ldots, m ; k=1,2, \ldots, t ; i \neq p,
\end{aligned}
$$

which satisfies support degrees conditions (1) (3) listed in Definition 14. $d\left(r_{i j}^{k}, r_{p j}^{k}\right)$ is the distance measure defined in (10) and (11).

Step 1.2. By use of attributes weighting vector $\omega=$ $\left(\omega_{1}, \omega_{2}, \ldots, \omega_{n}\right)^{T}$, calculate the weighted support degree $T\left(r_{i j}^{k}\right)$ of IVDHFUBLN $r_{i j}^{k}$ by other IVDHFUBLNs $r_{p j}^{k}(p=$ $1,2, \ldots, n ; p \neq i)$, where

$$
T\left(r_{i j}^{k}\right)=\sum_{p=1, p \neq i}^{n} \omega_{p} \sup \left(r_{i j}^{k}, r_{p j}^{k}\right)
$$

Step 1.3. Utilize weights $\eta_{k}(k=1,2, \ldots, t)$ for decisionmakers $d_{k}$ to calculate weights $\xi_{i j}^{k}$ associated with the IVDHFUBLN $r_{i j}^{k}$ :

$$
\xi_{i j}^{k}=\frac{\eta_{k}\left(1+T\left(r_{i j}^{k}\right)\right)}{\sum_{k=1}^{t} \eta_{k}\left(1+T\left(r_{i j}^{k}\right)\right)}, \quad k=1,2, \ldots, t
$$

where $\xi_{i j}^{k} \geq 0$ and $\sum_{k=1}^{t} \xi_{i j}^{k}=1$.

Step 1.4. Aggregate individual decision matrix $R^{k}=$ $\left(r_{i j}^{k}\right)_{n \times m}(k=1,2, \ldots, t)$ into group decision matrix $R=$ $\left(r_{i j}\right)_{n \times m}$ by W-IVDHFUBL-PA operator, where 


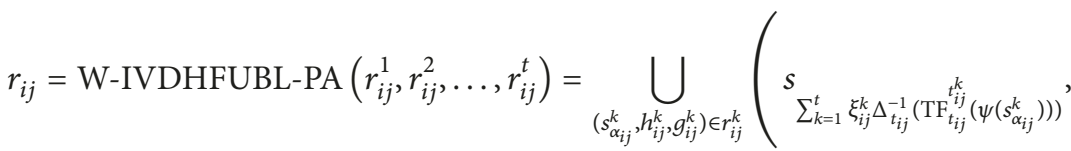

$$
\begin{aligned}
& \left.\bigcup_{\left.\left[\mu_{i j}^{L k}, \mu_{i j}^{U k}\right] \in \widetilde{h}_{i j}^{k}, \nu_{i j}^{L k}, \nu_{i j}^{U k}\right] \in \tilde{g}_{i j}^{k}}\left\{\left\{\left[1-\prod_{k=1}^{t}\left(1-\mu_{i j}^{L k}\right)^{\xi_{i j}^{k}}, 1-\prod_{k=1}^{t}\left(1-\mu_{i j}^{U k}\right)^{\xi_{i j}^{k}}\right]\right\},\left\{\left[\prod_{k=1}^{t}\left(v_{i j}^{L k}\right)^{\xi_{i j}^{k}}, \prod_{k=1}^{t}\left(v_{i j}^{U k}\right)^{\xi_{i j}^{k}}\right]\right\}\right\}\right),
\end{aligned}
$$

where $t_{i j}^{k}$ is the level of $\operatorname{LH}\left(s_{\alpha_{i j}}^{k}\right)$ and $t_{i j}$ is the maximum level of $t_{i j}^{k}$ in all the $\operatorname{LH}\left(s_{\alpha_{i j}}^{k}\right)(k=1,2, \ldots, t)$. And now, $r_{i j}$ reduces to the form of interval-valued dual hesitant fuzzy balanced linguistic numbers but with different granularity.

Step 1.5. Calculate support degrees $\sup \left(r_{i j}, r_{p j}\right)$ :

$$
\begin{aligned}
& \operatorname{supp}\left(r_{i j}, r_{p j}\right)=1-d\left(r_{i j}, r_{p j}\right), \\
& i, p=1,2, \ldots, n ; i \neq p ; j=1,2, \ldots, m,
\end{aligned}
$$

which satisfy support conditions (1) (3) in Definition 14 . Here, $d\left(r_{i j}, r_{p j}\right)$ are calculated by (18), (19), and (20).

Step 1.6. Calculate support degree $T\left(r_{i j}\right)$ of $r_{i j}$ by another $r_{p j}(p=1,2, \ldots, n ; p \neq i)$, where

$$
T\left(r_{i j}\right)=\sum_{p=1, p \neq i}^{n} \omega_{p} \operatorname{supp}\left(r_{i j}, r_{p j}\right) .
$$

Step 1.7 Calculate weighting vector $w_{i j}(i=1,2, \ldots, n ; j=$ $1,2, \ldots, m)$ associated with $r_{i j}$ :

$$
w_{i j}=\frac{\omega_{i}\left(1+T\left(r_{i j}\right)\right)}{\sum_{i=1}^{n} \omega_{i}\left(1+T\left(r_{i j}\right)\right)} \text {. }
$$

Step 1.8. Use W-IVDHFUBL-PA operator to aggregate all $r_{i j}(i=1,2, \ldots, n ; j=1,2, \ldots, m)$ into overall evaluation values $r_{j}$ corresponding to each alternative $A_{j}$ :

$$
\begin{aligned}
& r_{j}=\mathrm{W}-\mathrm{IVDHFUBL}-\mathrm{PA}\left(r_{1 j}, r_{2 j}, \ldots, r_{n j}\right)=\bigcup_{\left(s_{\alpha_{i j}} \widetilde{h}_{i j}, \widetilde{q}_{i j}\right) \in r_{i j}}\left(s_{\sum_{i=1}^{n} w_{i j} \Delta_{t j}^{-1}\left(\mathrm{TF}_{t_{j}}^{t_{i j}}\left(s_{\alpha_{i j}}\right)\right)},\right. \\
& \left.\bigcup_{\left[\mu_{i j}^{L}, \mu_{i j}^{U}\right] \in \widetilde{h}_{i j},\left[\nu_{i j}^{L}, \nu_{i j}^{U}\right] \in \widetilde{g}_{i j}}\left\{\left\{\left[1-\prod_{i=1}^{n}\left(1-\mu_{i j}^{L}\right)^{w_{i j}}, 1-\prod_{i=1}^{n}\left(1-\mu_{i j}^{U}\right)^{w_{i j}}\right]\right\},\left\{\left[\prod_{i=1}^{n}\left(v_{i j}^{L}\right)^{w_{i j}}, \prod_{i=1}^{n}\left(v_{i j}^{U}\right)^{w_{i j}}\right]\right\}\right\}\right),
\end{aligned}
$$

where $t_{i j}$ is the level of $\operatorname{LH}\left(s_{\alpha_{i j}}\right)$ and $t_{j}$ is the maximum level in all the attributes levels of $\operatorname{LH}\left(s_{\alpha_{i j}}\right)(i=1,2, \ldots, n)$.

Step 1.9. According to Definition 8 , calculate scores $s\left(r_{j}\right)$ of the overall values $r_{j}$ regarding alternatives $A_{j}(j=1,2, \ldots, m)$.

Step 1.10. Based on Definition 10, rank all alternatives $A_{j}(j=$ $1,2, \ldots, m)$ and select the most desirable one(s) in accordance with the rank orders of $r_{j}(j=1,2, \ldots, m)$.

Case 2. Suppose that the exact weighting vectors for both decision-makers and attributes are totally unknown due to problem complexity, but expertise attitudes on the relative importance among attributes, denoted as the order-inducing vector $u=\left(u_{1}, u_{2}, \ldots, u_{n}\right)$, can be determined according to collective opinions of all decision-makers. Therefore, based on individual decision matrices and the order-inducing vector $u$, we here utilize the I-IVDHFUBL-POWA operator to construct another approach for complex MAGDM under interval-valued dual hesitant fuzzy unbalanced linguistic environments, as described in Approach 2.

Approach 2. The second approach is MAGDM based on IVDHFUBLS: with totally unknown weighting information but reaching expertise attitudes on the relative importance among attributes.

Step 2.1. Taking the perceived relative importance among attributes as order-inducing vector $u=\left(u_{1}, u_{2}, \ldots, u_{n}\right)$, rearrange all the IVDHFUBLNs $r_{i j}^{k}(k=1,2,3)$ in individual decision matrix $R^{(k)}$ according to $u$ and then obtain the reordered individual decision matrix $R^{\sigma(k)}$.

Step 2.2. Calculate support degree $T\left(R^{\sigma(k)}\right)$ of the $k$ th reordered individual decision matrix $R^{\sigma(k)}$ from other reordered individual decision matrices $R^{\sigma(l)}(l=1,2, \ldots, t$; $l \neq k)$, where 


$$
T\left(R^{\sigma(k)}\right)=\frac{1}{m n(t-1)} \sum_{i=1}^{n} \sum_{j=1}^{m} \sum_{l=1, l \neq t}^{t} \sup \left(r_{i j}^{\sigma(k)}, r_{i j}^{\sigma(l)}\right)
$$

where

$$
\begin{aligned}
& \sup \left(r_{i j}^{\sigma(k)}, r_{i j}^{\sigma(l)}\right)=1-d\left(r_{i j}^{\sigma(k)}, r_{i j}^{\sigma(l)}\right), \\
& k, l=1,2, \ldots, t ; k \neq l ; i=1,2, \ldots, n ; j=1,2, \ldots, m,
\end{aligned}
$$

which satisfies conditions (1)-(3) in Definition 14. $d\left(r_{i j}^{\sigma(k)}, r_{i j}^{\sigma(l)}\right)$ is calculated by normalized Euclidean distance measure defined in (10) and (11).

Step 2.3. Calculate the power weights $\xi^{k}$ for decision-makers $d_{k}(k=1,2, \ldots, t)$ based on the support degree of reordered individual decision matrix $R^{\sigma(k)}$, according to

$$
\xi^{k}=\frac{\left(1+T\left(R^{\sigma(k)}\right)\right)}{\sum_{k=1}^{t}\left(1+T\left(R^{\sigma(k)}\right)\right)}, \quad k=1,2, \ldots, t .
$$

Step 2.4. Calculate support degrees of attributes in each reordered individual decision matrix:

$$
\begin{aligned}
& \sup \left(r_{i j}^{\sigma(k)}, r_{i j}^{\sigma(l)}\right)=1-d\left(r_{i j}^{\sigma(k)}, r_{i j}^{\sigma(l)}\right), \\
& k, l=1,2, \ldots, t ; k \neq l ; i=1,2, \ldots, n ; j=1,2, \ldots, m,
\end{aligned}
$$

which satisfies the conditions listed in Definition 14 . $d\left(r_{i j}^{\sigma(k)}, r_{i j}^{\sigma(l)}\right)$ is calculated by normalized Euclidean distance measure in (10) and (11).
Step 2.5. Calculate support degree $T\left(r_{i j}^{\sigma(k)}\right)$ of $r_{i j}^{\sigma(k)}$ from $r_{i j}^{\sigma(l)}(l=1,2, \ldots, t ; l \neq k)$ in each reordered individual decision matrix $R^{\sigma(k)}$, where

$$
T\left(r_{i j}^{\sigma(k)}\right)=\sum_{l=1, l \neq k}^{t} \sup \left(r_{i j}^{\sigma(k)}, r_{i j}^{\sigma(l)}\right) .
$$

Step 2.6. Utilize (26) to calculate weights $\eta_{i j}^{\sigma(k)}$ associated with $r_{i j}^{\sigma(k)}$ in each reordered individual decision matrix $R^{\sigma(k)}$, where

$$
\begin{aligned}
& \eta_{i j}^{\sigma(k)}=g\left(\frac{\widehat{R}^{k}}{T V}\right)-g\left(\frac{\widehat{R}^{k-1}}{T V}\right) \\
& \text { with } \eta_{i j}^{k} \in[0,1], \sum_{k=1}^{t} \eta_{i j}^{k}=1, g \text { is the BUM function, } \\
& \widehat{R}^{k}=\sum_{l=1}^{k} V_{i j}^{\sigma(l)} \\
& T V_{i j}=\sum_{l=1}^{t} V_{i j}^{\sigma(l)}, \\
& V_{i j}^{\sigma(l)}=1+T\left(r_{i j}^{\sigma(l)}\right) .
\end{aligned}
$$

Step 2.7. Aggregate each reordered individual decision matrix $R^{\sigma(k)}=\left(r_{i j}^{\sigma(k)}\right)_{n \times m}(k=1,2, \ldots, t)$ into its overall decision matrix $\bar{R}^{k}=\left(r_{j}^{k}\right)_{1 \times m}(k=1,2, \ldots, t)$, respectively, by use of the I-IVDHFUBL-POWA operator:

$$
\begin{aligned}
& r_{j}^{k}=\operatorname{I-IVDHFUBL-POWA}\left(r_{1 j}^{\sigma(k)}, r_{2 j}^{\sigma(k)}, \ldots, r_{n j}^{\sigma(k)}\right)=\bigcup_{\left(s_{\alpha_{i j}}^{\sigma(k)} \tilde{h}_{i j}^{\sigma(k)}, \tilde{g}_{i j}^{\sigma(k)}\right) \in r_{i j}^{\sigma(k)}}\left(s_{\sum_{i=1}^{n} \eta_{i j}^{\sigma(k)} \Delta^{-1}\left(\operatorname{TF}_{t_{j}^{(\sigma)}}^{t_{i j}^{\sigma(k)}}\left(\psi\left(s_{\alpha_{i j}}^{\sigma(k)}\right)\right)\right)}\right. \\
& \left.\bigcup_{\left[\mu_{i j}^{L \sigma(k)}, \mu_{i j}^{U \sigma(k)}\right] \in \tilde{h}_{i j}^{\sigma(k)},\left[v_{i j}^{L \sigma(k)}, \nu_{i j}^{U \sigma(k)}\right] \in \widetilde{g}_{i j}^{\sigma(k)}}\left\{\left\{\left[1-\prod_{i=1}^{n}\left(1-\mu_{i j}^{L \sigma(k)}\right)^{\eta_{i j}^{\sigma(k)}}, 1-\prod_{i=1}^{n}\left(1-\mu_{i j}^{U \sigma(k)}\right)^{\eta_{i j}^{\sigma(k)}}\right]\right\},\left\{\left[\prod_{i=1}^{n}\left(v_{i j}^{L \sigma(k)}\right)^{\eta_{i j}^{\sigma(k)}}, \prod_{i=1}^{n}\left(v_{i j}^{U \sigma(k)}\right)^{\eta_{i j}^{\sigma(k)}}\right]\right\}\right\}\right),
\end{aligned}
$$

where $t_{i j}^{\sigma(k)}$ is the level of $\operatorname{LH}\left(s_{\alpha_{i j}}^{\sigma(k)}\right)$ and $t_{j}^{\sigma(k)}$ is the maximum level of $t_{i j}^{\sigma(k)}$ in all attributes levels of $\operatorname{LH}\left(s_{\alpha_{i j}}^{\sigma(k)}\right)(i=$ $1,2, \ldots, n)$.
Step 2.8. Utilize the IVDHFL-PA operator described in (24) to aggregate all the individual overall evaluation values $r_{j}^{k}(k=$ $1,2, \ldots, t ; j=1,2, \ldots, m)$ into the group overall evaluation values $r_{j}(j=1,2, \ldots, m)$ of each alternative $A_{j}(j=$ $1,2, \ldots, m)$ :

$$
\begin{aligned}
& r_{j}=\operatorname{IVDHFL}-\mathrm{PA}\left(r_{j}^{1}, r_{j}^{2}, \ldots, r_{j}^{t}\right)=\bigcup_{\left(s_{\alpha_{j}^{k}}, \widetilde{h}_{j}^{k}, g_{j}^{k}\right) \in r_{j}^{k}}\left(s_{\sum_{k=1}^{t} \xi^{k} \Delta_{t_{0}}^{-1}\left(\mathrm{TF}_{t_{0}}^{t_{j}^{k}}\left(s_{\alpha_{j}^{k}}\right)\right)},\right. \\
& \left.\bigcup_{\left[\mu_{j}^{k L}, \mu_{j}^{k U}\right] \in \tilde{h}_{j}^{k},\left[\nu_{j}^{k L}, \nu_{j}^{k U}\right] \in \tilde{g}_{j}^{k}}\left\{\left\{\left[1-\prod_{k=1}^{t}\left(1-\mu_{j}^{k L}\right)^{\xi^{k}}, 1-\prod_{j=1}^{m}\left(1-\mu_{j}^{k U}\right)^{\xi^{k}}\right]\right\},\left\{\left[\prod_{k=1}^{t}\left(v_{j}^{k L}\right)^{\xi^{k}}, \prod_{k=1}^{t}\left(v_{j}^{k U}\right)^{\xi^{k}}\right]\right\}\right\}\right)
\end{aligned}
$$




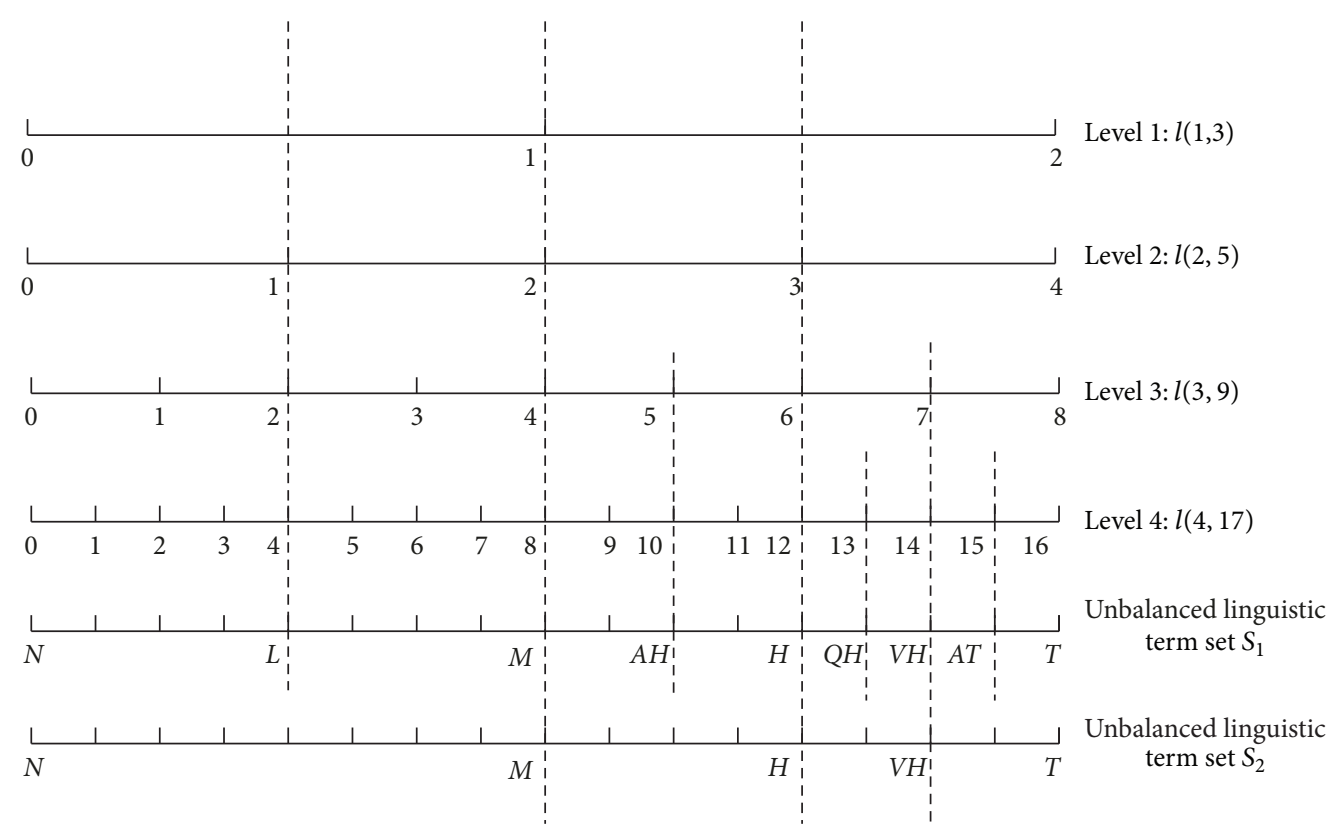

FIGURE 1: Unbalanced linguistic term sets $\left(S_{1}\right.$ and $\left.S_{2}\right)$ and their mapping in linguistic hierarchies.

where $t_{j}^{k}$ is the level of $\operatorname{LH}\left(s_{\alpha_{j}^{k}}\right)$ and $t_{0}$ is the maximum in all levels of $\operatorname{LH}\left(s_{\alpha_{j}^{1}}\right), \operatorname{LH}\left(s_{\alpha_{j}^{2}}\right), \ldots, \operatorname{LH}\left(s_{\alpha_{j}^{k}}\right)(k=1,2, \ldots, t)$.

Step 2.9. Calculate scores $s\left(r_{j}\right)$ of the group overall evaluation values $r_{j}(j=1,2, \ldots, m)$ corresponding to alternatives $A_{j}(j=1,2, \ldots, m)$ according to Definition 8 .

Step 2.10. Based on the rules described in Definition 10, rank all the alternatives $A_{j}(j=1,2, \ldots, m)$ and select the most desirable one (s) in accordance with the rank orders of $r_{j}(j=$ $1,2, \ldots, m)$.

4.2. Illustrative Example. In this section, we adapt the fashion design evaluation problem in [40] as illustrative study to verify our proposed MAGDM approaches.

Suppose that an apparel firm is considering its fashion design for forthcoming season. Choose eight attributes $C_{i}(i=1,2, \ldots, 8)$ [40] which have been determined to evaluate three design solutions $A_{j}(j=1,2,3)$ after screening: $C_{1}$ : Opponent Ability; $C_{2}$ : Fashion Forecast; $C_{3}$ : Product Position; $C_{4}$ : Consumer Cognition; $C_{5}$ : Consumer Lifestyle; $C_{6}$ : Brand Image; $C_{7}$ : New Idea; $C_{8}$ : Theme Story. A panel of three decision-makers $D_{k}(k=1,2,3)$, including a filtered customer, a marketing expert, and a firm's fashion designer, has been organized to provide their preferences on response solutions $A_{j}(j=1,2,3)$, by use of the developed tool of IVDHFUBLS.

The corresponding linguistic variables are chosen from two unbalanced linguistic term sets $S_{1}$ and $S_{2}$, where $S_{1}=\{N, L, M, A H, H, Q H, V H, A T, T\}$ and $S_{2}=\{N, M, H, V H, T\}$. The relationship between unbalanced linguistic term sets $S_{1}, S_{2}$ and linguistic hierarchies is shown in Figure 1. Decision-makers $D_{1}$ and $D_{2}$ evaluate three emergency response solutions by the unbalanced linguistic term set $S_{1}$, while $D_{3}$ utilize the unbalanced linguistic term set $S_{2}$. Then, three decision matrices, that is, $R^{k}=\left(r_{i j}^{k}\right)_{8 \times 3}(k=1,2,3)$, are collected and shown in Tables $1-3$.

Subsequently, we apply Approaches 1 and 2 to resolve this evaluation problem.

As for Approach 1, we suppose weighting vectors for both decision-makers and attributes are already known: the weighting vector $\eta=(0.3,0.4,0.3)^{T}$ for the three decision-makers and the weighting vector $\omega=(0.1,0.1,0.05,0.1,0.05,0.2,0.2,0.2)^{T}$ for the eight attributes.

Regarding Approach 2, we suppose the weighting vector $\eta$ for decision-makers and the weighting vector $\omega$ for attributes are totally unknown. After comprehensively recognizing actual decision scenarios, the panel of three decision-makers reaches a consensus on the relative importance of the eight attributes, that is, $C_{8}>C_{7}>C_{6}>C_{2}>C_{1}>C_{4}>$ $C_{5}>C_{3}$. To include these expertise attitudes, we take the relative importance among attributes as an order-inducing vector $u=(8,7,6,2,1,4,5,3)$ for Approach 2 .

The ranking results by Approaches 1 and 2 have been listed in Table 4 for comparison. As can be seen from Table 4, Approaches 1 and 2 unanimously identified the ranking order of $A_{2}>A_{3}>A_{1}$ for the three design solutions, while, according to the score values yielded by the two approaches, Approach 2 can tell apart the superiority of solution $A_{2}$ and inferiority of solution $A_{1}$ more clearly than Approach 1. Reasons can be basically observed from the facts shown in Table 4. Referring to scores for all response solutions obtained by the two approaches, $A_{1}$ is obviously inferior to the other two solutions and $A_{2}$ is obviously superior to the 
TABLE 1: Decision matrix $R^{1}$ with IVDHFUBLNs.

\begin{tabular}{|c|c|c|c|}
\hline & $A_{1}$ & $A_{2}$ & $A_{3}$ \\
\hline$C_{1}$ & $\begin{array}{c}(V H,\{[0.2,0.3]\} \\
\{[0.2,0.4],[0.3,0.4]\})\end{array}$ & $\begin{array}{c}(A T,\{[0.4,0.5],[0.5,0.6]\} \\
\quad\{[0.2,0.3],[0.2,0.4]\})\end{array}$ & $\begin{array}{c}(L,\{[0.1,0.2],[0.1,0.3]\} \\
\{[0.6,0.7]\})\end{array}$ \\
\hline$C_{2}$ & $\begin{array}{l}(H,\{[0.5,0.6]\} \\
\quad\{[0.2,0.3]\})\end{array}$ & $\begin{array}{l}(T,\{[0.6,0.7]\} \\
\quad\{[0.1,0.2]\})\end{array}$ & $\begin{array}{c}(H,\{[0.2,0.3]\}, \\
\{[0.5,0.6],[0.6,0.7]\})\end{array}$ \\
\hline$C_{3}$ & $\begin{array}{c}(M,\{[0.3,0.4]\}, \\
\{[0.4,0.5],[0.5,0.6]\})\end{array}$ & $\begin{array}{c}(L,\{[0.6,0.7],[0.7,0.8]\}, \\
\{[0.1,0.2]\})\end{array}$ & $\begin{array}{c}(A H,\{[0.4,0.5]\} \\
\quad\{[0.2,0.3]\})\end{array}$ \\
\hline$C_{4}$ & $\begin{array}{l}(T,\{[0.2,0.4]\} \\
\quad\{[0.5,0.6]\})\end{array}$ & $\begin{array}{l}(Q H,\{[0.3,0.5]\} \\
\quad\{[0.2,0.3]\})\end{array}$ & $\begin{array}{c}(V H,\{[0.6,0.7]\} \\
\{[0.1,0.2],[0.2,0.3]\})\end{array}$ \\
\hline$C_{5}$ & $\begin{array}{c}(L,\{[0.4,0.5]\} \\
\{[0.1,0.2],[0.4,0.5]\})\end{array}$ & $\begin{array}{l}(M,\{[0.6,0.7]\} \\
\quad\{[0.1,0.2]\})\end{array}$ & $\begin{array}{c}(M,\{[0.4,0.5],[0.6,0.7]\} \\
\{[0.1,0.3]\})\end{array}$ \\
\hline$C_{6}$ & $\begin{array}{c}(M,\{[0.1,0.2],[0.3,0.5]\} \\
\{[0.3,0.5]\})\end{array}$ & $\begin{array}{c}(V H,\{[0.2,0.4],[0.5,0.6]\} \\
\{[0.2,0.3]\})\end{array}$ & $\begin{array}{l}(H,\{[0.3,0.4]\} \\
\quad\{[0.4,0.5]\})\end{array}$ \\
\hline$C_{7}$ & $\begin{array}{c}(A H,\{[0.4,0.5],[0.5,0.6]\} \\
\quad\{[0.2,0.3],[0.2,0.4]\})\end{array}$ & $\begin{array}{c}(L,\{[0.5,0.6],[0.7,0.8]\} \\
\{[0.1,0.2]\})\end{array}$ & $\begin{array}{c}(Q H,\{[0.4,0.5],[0.5,0.6]\} \\
\{[0.3,0.4]\})\end{array}$ \\
\hline$C_{8}$ & $\begin{array}{l}(L,\{[0.1,0.3]\} \\
\quad\{[0.4,0.6]\})\end{array}$ & $\begin{array}{c}(H,\{[0.5,0.7]\} \\
\{[0.1,0.2],[0.2,0.3]\})\end{array}$ & $\begin{array}{c}(V H,\{[0.4,0.6]\} \\
\quad\{[0.3,0.4]\})\end{array}$ \\
\hline
\end{tabular}

TABLE 2: Decision matrix $R^{2}$ with IVDHFUBLNs.

\begin{tabular}{|c|c|c|c|}
\hline & $A_{1}$ & $A_{2}$ & $A_{3}$ \\
\hline$C_{1}$ & $\begin{array}{l}(M,\{[0.3,0.5]\} \\
\quad\{[0.1,0.2]\})\end{array}$ & $\begin{array}{l}(A T,\{[0.4,0.7]\} \\
\quad\{[0.2,0.3]\})\end{array}$ & $\begin{array}{l}(A T,\{[0.6,0.8]\} \\
\quad\{[0.1,0.2]\})\end{array}$ \\
\hline$C_{2}$ & $\begin{array}{c}(A H,\{[0.1,0.4]\} \\
\{[0.2,0.3],[0.3,0.4]\})\end{array}$ & $\begin{array}{l}(L,\{[0.5,0.6]\} \\
\quad\{[0.1,0.2]\})\end{array}$ & $\begin{array}{c}(H,\{[0.4,0.5]\} \\
\{[0.3,0.4],[0.4,0.5]\})\end{array}$ \\
\hline$C_{3}$ & $\begin{array}{c}(H,\{[0.2,0.4]\} \\
\quad\{[0.4,0.5]\})\end{array}$ & $\begin{array}{c}(A H,\{[0.6,0.7],[0.7,0.8]\} \\
\{[0.1,0.2]\})\end{array}$ & $\begin{array}{l}(H,\{[0.4,0.5]\} \\
\quad\{[0.2,0.3]\})\end{array}$ \\
\hline$C_{4}$ & $\begin{array}{c}(\mathrm{QH},\{[0.2,0.4]\} \\
\quad\{[0.5,0.6]\})\end{array}$ & $\begin{array}{c}(M,\{[0.2,0.3]\} \\
\{[0.5,0.6],[0.6,0.7]\})\end{array}$ & $\begin{array}{c}(A H,\{[0.4,0.5]\} \\
\quad\{[0.2,0.3]\})\end{array}$ \\
\hline$C_{5}$ & $\begin{array}{c}(M,\{[0.1,0.2],[0.2,0.3]\} \\
\{[0.1,0.2]\})\end{array}$ & $\begin{array}{c}(V H,\{[0.6,0.7]\} \\
\quad\{[0.1,0.2]\})\end{array}$ & $\begin{array}{c}(\mathrm{QH},\{[0.4,0.5]\} \\
\quad\{[0.3,0.4]\})\end{array}$ \\
\hline$C_{6}$ & $\begin{array}{l}(L,\{[0.6,0.7]\} \\
\quad\{[0.1,0.2]\})\end{array}$ & $\begin{array}{c}(A T,\{[0.2,0.3]\} \\
\quad\{[0.5,0.7]\})\end{array}$ & $\begin{array}{c}(L,\{[0.7,0.8]\} \\
\quad\{[0.1,0.2]\})\end{array}$ \\
\hline$C_{7}$ & $\begin{array}{c}(H,\{[0.3,0.4]\} \\
\{[0.2,0.3],[0.4,0.5]\})\end{array}$ & $\begin{array}{l}(H,\{[0.5,0.8]\} \\
\quad\{[0.1,0.2]\})\end{array}$ & $\begin{array}{c}(V H,\{[0.2,0.5]\} \\
\quad\{[0.3,0.4]\})\end{array}$ \\
\hline$C_{8}$ & $\begin{array}{c}(M,\{[0.5,0.7]\}, \\
\quad\{[0.2,0.3]\}) \\
\end{array}$ & $\begin{array}{l}(A T,\{[0.3,0.5]\} \\
\quad\{[0.3,0.4]\})\end{array}$ & $\begin{array}{l}(H,\{[0.3,0.5]\} \\
\quad\{[0.3,0.4]\})\end{array}$ \\
\hline
\end{tabular}

TABLE 3: Decision matrix $R^{3}$ with IVDHFUBLNs.

\begin{tabular}{|c|c|c|c|}
\hline & $A_{1}$ & $A_{2}$ & $A_{3}$ \\
\hline$C_{1}$ & $\begin{array}{l}(M,\{[0.6,0.8]\} \\
\quad\{[0.1,0.2]\})\end{array}$ & $\begin{array}{l}(T,\{[0.3,0.4]\} \\
\quad\{[0.4,0.6]\})\end{array}$ & $\begin{array}{c}(V H,\{[0.4,0.5]\}, \\
\{[0.1,0.2],[0.3,0.4]\})\end{array}$ \\
\hline$C_{2}$ & $\begin{array}{l}(H,\{[0.4,0.5]\} \\
\quad\{[0.4,0.5]\})\end{array}$ & $\begin{array}{c}(M,\{[0.4,0.5],[0.5,0.6]\} \\
\{[0.2,0.3]\})\end{array}$ & $\begin{array}{c}(V H,\{[0.7,0.8]\} \\
\quad\{[0.1,0.2]\})\end{array}$ \\
\hline$C_{3}$ & $\begin{array}{c}(H,\{[0.2,0.4],[0.3,0.4]\} \\
\{[0.2,0.3]\})\end{array}$ & $\begin{array}{c}(V H,\{[0.6,0.7]\} \\
\{[0.1,0.3]\})\end{array}$ & $\begin{array}{l}(H,\{[0.6,0.8]\} \\
\quad\{[0.1,0.2]\})\end{array}$ \\
\hline$C_{4}$ & $\begin{array}{c}(M,\{[0.7,0.8]\} \\
\{[0.1,0.2]\})\end{array}$ & $\begin{array}{c}(H,\{[0.1,0.3],[0.2,0.4]\} \\
\{[0.3,0.5]\})\end{array}$ & $\begin{array}{c}(M,\{[0.6,0.7]\} \\
\quad\{[0.1,0.3]\})\end{array}$ \\
\hline$C_{5}$ & $\begin{array}{l}(T,\{[0.2,0.5]\} \\
\quad\{[0.3,0.5]\})\end{array}$ & $\begin{array}{c}(M,\{[0.4,0.6],[0.5,0.7]\} \\
\{[0.1,0.2]\})\end{array}$ & $\begin{array}{l}(V H,\{[0.6,0.7]\}, \\
\quad\{[0.1,0.2]\})\end{array}$ \\
\hline$C_{6}$ & $\begin{array}{c}(V H,\{[0.6,0.7]\}, \\
\quad\{[0.2,0.3]\})\end{array}$ & $\begin{array}{c}(V H,\{[0.3,0.6]\} \\
\{[0.1,0.3],[0.2,0.4]\})\end{array}$ & $\begin{array}{l}(M,\{[0.5,0.6]\} \\
\quad\{[0.3,0.4]\})\end{array}$ \\
\hline$C_{7}$ & $\begin{array}{l}(M,\{[0.1,0.2]\} \\
\quad\{[0.5,0.8]\})\end{array}$ & $\begin{array}{l}(H,\{[0.4,0.6]\} \\
\quad\{[0.3,0.4]\})\end{array}$ & $\begin{array}{l}(H,\{[0.3,0.5]\} \\
\quad\{[0.4,0.5]\})\end{array}$ \\
\hline$C_{8}$ & $\begin{array}{c}(V H,\{[0.3,0.4]\}, \\
\{[0.1,0.3],[0.2,0.5]\})\end{array}$ & $\begin{array}{c}(V H,\{[0.7,0.8]\}, \\
\quad\{[0.1,0.2]\})\end{array}$ & $\begin{array}{c}(H,\{[0.6,0.7]\} \\
\quad\{[0.1,0.3]\})\end{array}$ \\
\hline
\end{tabular}


TABLE 4: Comparisons between Approaches 1 and 2 on their ranking results and accepted relative importance among attributes.

\begin{tabular}{|c|c|c|c|}
\hline Approaches & $\begin{array}{c}\text { Ranking } \\
\text { results }\end{array}$ & $\begin{array}{c}\text { Corresponding } \\
\text { scores }\end{array}$ & Accepted relative importance among attributes \\
\hline Approach 1 & $A_{2}>A_{3}>A_{1}$ & $\begin{array}{c}s\left(r_{2}\right)=0.2231 \\
s\left(r_{3}\right)=0.1737 \\
s\left(r_{1}\right)=0.093\end{array}$ & $\begin{array}{l}\text { Approach } 1 \text { accepted the known attributes } \\
\text { weighting vector } \\
\begin{array}{c}w=(0.1,0.1,0.05,0.1,0.05,0.2,0.2,0.2)^{T} \\
\text { which indicates the relative importance among }\end{array} \\
\text { attributes as } \\
\left(C_{8}=C_{7}=C_{6}\right) \succ\left(C_{2}=C_{1}=C_{4}\right)>\left(C_{5}=C_{3}\right) .\end{array}$ \\
\hline Approach 2 & $A_{2}>A_{3}>A_{1}$ & $\begin{array}{c}s\left(r_{2}\right)=0.2288 \\
s\left(r_{3}\right)=0.168 \\
s\left(r_{1}\right)=0.0926\end{array}$ & $\begin{array}{c}\text { According to collective opinions on interrelations } \\
\text { among assessing attributes, Approach } 2 \text { accepted } \\
\text { the following relative importance among } \\
\text { attributes: } \\
C_{8}>C_{7}>C_{6}>C_{2}>C_{1}>C_{4}>C_{5}>C_{3} \\
\text { as the order inducing vector. }\end{array}$ \\
\hline
\end{tabular}

other two; thus both ranking orders for total three solutions are the same. Approach 2 increases the score of best solution $A_{2}$ from 0.2231 to 0.2288 , decreases the score of $A_{3}$ from 0.1737 to 0.168 , and also decreases the score of worse solution $A_{1}$ from 0.093 to 0.0926 . Along with changes in scores of design solutions, Approaches 1 and 2 both still identify the same disparity patterns in scores; Approach 2 reinforces the positions of $A_{2}$ and $A_{1}$ as the best and worst solutions, respectively.

From another perspective of observation, relative importance among attributes in Approach 2 was determined from the group opinions rather than holdover from earlier experience as in Approach 1; thus Approach 2 is more pertinent to practical problems. As shown in Table 4, the attributes weighting vector $w=(0.1,0.1,0.05,0.1,0.05,0.2,0.2,0.2)^{T}$ in Approach 1 indicates a relative importance as $\left(C_{8}=C_{7}=\right.$ $\left.C_{6}\right)>\left(C_{2}=C_{1}=C_{4}\right)>\left(C_{5}=C_{3}\right)$, which means experience weighting vector $w$, probably for general purpose, only roughly differentiates those attributes as three groups, where attributes share the same importance level. Interestingly, however, regarding Approach 2, the panel of decisionmakers derived relative importance among attributes as $C_{8}>$ $C_{7}>C_{6}>C_{2}>C_{1}>C_{4}>C_{5}>C_{3}$, which not only maintains the general cognition about product design as denoted in Approach 1, but also gives clearer differentiation among all attributes. Therefore, Approaches 1 and 2 both identified the same worst solution and the same best solution consistently from three alternatives, and
Approach 2 is capable of identifying their differences more clearly with considering group opinions.

4.3. Comparative Study. To further inspect the effectiveness of formerly developed approaches, in this subsection, we conduct comparative studies with conventional MAGDM approaches of TOPSIS-based methodology [41] and aggregation-operator-based methodology [42], respectively.

Regarding the same case addressed by Approach 1, we construct the aggregation-operator-based Approach 3, which utilizes an interval-valued dual hesitant fuzzy unbalanced linguistic weighted aggregation (IVDHFUBL-WA) operator for information fusion. Approach 3 takes the same attributes weighting vector $\omega$ and the same weighting vector $\eta$ for decision-makers as in Approach 1. Detailed processing steps in Approach 3 are shown below.

Approach 3. The third approach is MAGDM based on IVDHFUBL-WA operator.

Step 3.1. By use of attributes weighting vector $\omega$ and the following IVDHFUBL-WA operator, we aggregate individual decision matrices $R^{k}=\left(r_{i j}^{k}\right)_{n \times m}(k=1,2, \ldots, t)$ into individual overall evaluation values $r_{j}^{k}(j=1,2, \ldots, m ; k=$ $1,2, \ldots, t)$ for each alternative $A_{j}$. According to Xu [42], we derive the IVDHFUBL-WA operator as

$$
\begin{aligned}
& r_{j}^{k}=\operatorname{IVDHFUBL-WA}\left(r_{i j}^{1}, r_{i j}^{2}, \ldots, r_{i j}^{t}\right)=\bigcup_{\left(s_{\alpha_{i j}}^{k}, h_{i j}^{k}, g_{i j}^{k}\right) \in r_{i j}^{k}}\left(s_{\sum_{i=1}^{n} w_{i} \Delta_{t_{i j}}^{-1}\left(T_{t_{i j}}^{t_{i j}^{k}}\left(\psi\left(s_{\alpha_{i j}}^{k}\right)\right)\right)}^{,}\right. \\
& \left.\bigcup_{\left[\mu_{i j}^{L k}, \mu_{i j}^{U k}\right] \in \widetilde{h}_{i j}^{k},\left[\nu_{i j}^{L k}, \nu_{i j}^{U k}\right] \in \tilde{g}_{i j}^{k}}\left\{\left\{\left[1-\prod_{k=1}^{t}\left(1-\mu_{i j}^{L k}\right)^{w_{i}}, 1-\prod_{k=1}^{t}\left(1-\mu_{i j}^{U k}\right)^{w_{i}}\right]\right\},\left\{\left[\prod_{k=1}^{t}\left(\nu_{i j}^{L k}\right)^{w_{i}}, \prod_{k=1}^{t}\left(\nu_{i j}^{U k}\right)^{w_{i}}\right]\right\}\right\}\right) .
\end{aligned}
$$

Step 3.2. Use IVDHFUBL-WA operator and weighting vector $\eta$ to aggregate all the individual overall evaluation values $r_{j}^{k}(j=1,2, \ldots, m ; k=1,2, \ldots, t)$ to group overall evaluation values $r_{j}$ corresponding to each alternative $A_{j}$. 
TABLE 5: Comparisons on ranking results obtained by four approaches.

\begin{tabular}{lcc}
\hline Approaches & Ranking results & Corresponding scores \\
\hline $\begin{array}{l}\text { Approach 1 } \\
\text { Case 1) }\end{array}$ & $A_{2}>A_{3}>A_{1}$ & $s\left(r_{2}\right)=0.2231, s\left(r_{3}\right)=0.1737, s\left(r_{1}\right)=0.093$ \\
$\begin{array}{l}\text { Approach 2 } \\
\text { Case 2) }\end{array}$ & $A_{2}>A_{3}>A_{1}$ & $s\left(r_{2}\right)=0.2288, s\left(r_{3}\right)=0.168, s\left(r_{1}\right)=0.0926$ \\
$\begin{array}{l}\text { Approach 3 } \\
\text { (Case 1) }\end{array}$ & $A_{2}>A_{3}>A_{1}$ & $s\left(r_{2}\right)=0.2309, s\left(r_{3}\right)=0.1648, s\left(r_{1}\right)=0.0902$ \\
$\begin{array}{l}\text { Approach } 4 \\
\text { (Case 2) }\end{array}$ & $A_{3}>A_{2}>A_{1}$ & $c\left(r_{3}\right)=0.5919, c\left(r_{2}\right)=0.5622, c\left(r_{1}\right)=0.5424$ \\
\hline
\end{tabular}

Step 3.3. Calculate scores $s\left(r_{j}\right)(j=1,2, \ldots, m)$ of overall evaluation values $r_{j}$ of alternatives $A_{j}$ by Definition 8 .

Step 3.4. Rank alternatives $A_{j}(j=1,2, \ldots, m)$ in accordance with the scores $s\left(r_{j}\right)$.

As for the same case addressed by Approach 2, we construct TOPSIS-based Approach 4, which extends TOPSIS to group decision-making situations and also accepts relative importance relations among assessing attributes as adopted in Approach 2. Detailed processing steps in Approach 4 are shown below.

Approach 4. The fourth approach is MAGDM based on TOPSIS and IVDHFUBL-WA operator.

Step 4.1. See Step 2.1 of Approach 2.

Step 4.2. According to importance relations among assessing attributes, utilize Yager's RIM (regular increasing monotone) quantifier [43] to obtain position weighting vector for attributes. Then by use of the IVDHFUBL-WA operator introduced in (44), aggregate individual decision matrices $R^{\sigma(k)}=\left(r_{i j}^{\sigma(k)}\right)_{n \times m}$ into individual overall evaluation values $r_{j}^{k}$ for each alternative $A_{j}$, where $j=1,2, \ldots, m, k=1,2, \ldots, t$.

Step 4.3. Calculate the separating measure from positive and negative ideal solutions. Determine positive ideal solution (PIS) $r^{+}=\left(r_{1}^{+}, r_{2}^{+}, \ldots, r_{k}^{+}, \ldots, r_{t}^{+}\right)$and negative ideal solution (NIS) $r^{-}=\left(r_{1}^{-}, r_{2}^{-}, \ldots, r_{k}^{-}, \ldots, r_{t}^{-}\right)$, where $r_{k}^{+}=$ $(\{[1,1]\},\{[0,0]\})$ and $r_{k}^{-}=(\{[0,0]\},\{[1,1]\})$. Then we can calculate the separating measures $d_{j}^{+}$and $d_{j}^{-}$from the PIS and NIS for each alternative according to the distance measure defined in (10), where

$$
\begin{aligned}
& d_{j}^{+}=\sum_{k=1}^{t} d\left(r_{j}^{k}, r_{k}^{+}\right), \\
& d_{j}^{-}=\sum_{k=1}^{t} d\left(r_{j}^{k}, r_{k}^{-}\right) .
\end{aligned}
$$

Step 4.4. Calculate the relative closeness to the ideal solution, where

$$
c_{j}=\frac{d_{j}^{-}}{d_{j}^{-}+d_{j}^{+}} .
$$

Step 4.5. Rank the emergency alternatives according to the descending order of $c_{j}$.

Now we apply Approaches 3 and 4 to the cases in Section 4.2. For more clarity, ranking results obtained by the four approaches have been collected in Table 5 .

As can be seen from Table 5, the former three approaches clearly differentiated all three design solutions with the same ranking order of $A_{2}>A_{3}>A_{1}$; however, the TOPSIS-based Approach 4 yielded different ranking result of $A_{3}>A_{2}>A_{1}$ and the differences among scores of the three alternatives are relatively slight.

Regarding Case 1, Approaches 1 and 3 obtained the same ranking order $A_{2}>A_{3}>A_{1}$ for the three solutions. Although Approach 1 comprehensively considers supportive relations among attribute values by use of power aggregation operator, the scores of three alternatives are in slight difference after balancing by the same weighting vectors $\omega$ and $\eta$ during their information fusion steps.

Concerning Case 1 targeted by Approaches 2 and 4, they both identified the solution $A_{1}$ as the worst one as other approaches did, but the ranking relations between $A_{1}$ and $A_{1}$ are different. Differing from Approach 3, the TOPSIS-based Approach 4 adopted Yager's artificial estimation method to deduce attributes weighting vectors without taking into account the supportive relations among assessments; thus this will cause some potential information distortion. As a result, ranking result obtained by Approach 4 is different from other three approaches; scores of the three solutions are rather close even for the worst solution $A_{1}$, while Approach 2 managed to clearly differentiate the three solutions, especially for the worst solution $A_{1}$.

In summary, the proposed Approaches 1 and 2 are both effective multiple attributes group decision-making methods. For those decision situations where experience weighting information exists, Approach 1 can accommodate the weighing information in its decision-making procedures. Regarding those more complex decision situations where no concrete weighting information exists, Approach 2 manages to objectively derive unknown weights from decision matrices and also provides an effective way to enhance its decision-making process by integrating relative importance among assessing attributes as its order-inducing vector, which is derived from group opinions and generally cannot be adequate enough in practical problems of high uncertainty. 


\section{Conclusions}

To support rational decision-making activities under complex decision environments, we have proposed the intervalvalued dual hesitant fuzzy unbalanced linguistic set (IVDHFUBLS) to elicit complicate preferences of decision-makers more completely and flexibly, which not only allows decisionmakers to follow their cognition habit by marking their most approximate linguistic term in an unbalanced linguist label system, but also allows them to supplement the designated label with two sets of interval-valued membership degrees and nonmembership degrees. IVDHFUBLS manages to attain flexibility of interval values in assigning membership and nonmembership degrees, as well as the advantages of both unbalanced linguistic set and dual hesitant fuzzy set in depicting fuzzy properties of evaluating objects. We have defined operational laws for the IVDHFUBLS, and, more importantly, a novel distance measure has been put forward to overcome potential information distortion that could be caused by conventional distance measure widely adopted for hesitant fuzzy set and its hybrid extensions.

In view of the intrinsic suitability of classic power aggregation operators and induced aggregation operators in constructing MAGDM approaches for complex problems, such as those scenarios where only limited decision information can be exploited objectively based on supportive interrelations among attribute values or where additional expertise attitudes should be included in decision-making procedures, we have developed the W-IVDHFUBL-PA operator, the IVDHFUBL-PA operator, and the I-IVDHFUBL-POWA operator. Their desirable properties, including commutativity, idempotency, boundedness, and monotonicity, have been further inspected. Then, based on the W-IVDHFUBL-PA operator and I-IVDHFUBL-POWA operator, we have structured two approaches of Approaches 1 and 2, respectively. Numerical studies have verified effectiveness and practicality of the both approaches. In particular, Approach 2 is capable of objectively deriving unknown weights from decision matrices and also provides an effective way to enhance its decisionmaking process by integrating additional expertise attitudes in complex decision-making situations.

Due to continuously emerging complex decision-making problems, such as sustainable investment projects evaluation and complicate green supplier selection, future research directions should be still aimed at approaches by considering more interrelations among decision factors as well as application studies.

\section{Appendix}

\section{A. Transformation between 2-Tuple Linguistic Representation and Unbalanced Linguistic Variable}

(1) Representation in linguistic hierarchy: to transform the unbalanced terms of $S$ into the corresponding terms in the $\mathrm{LH}$, transformation function $\psi$ is employed to associate each unbalanced linguistic 2-tuple $\left(s_{i}, \alpha\right)$ with its linguistic 2-tuple in $\mathrm{LH}(\bar{S})$; that is,

$$
\psi: \bar{S} \longrightarrow \operatorname{LH}(\bar{S}),
$$

so that $\psi\left(s_{i}, \alpha\right)=\left(s_{I(i)}^{G(i)}, \lambda\right)$, for $\forall\left(s_{i}, \alpha\right) \in \bar{S}$.

(2) Computational phase: firstly, transform $\left(s_{I(i)}^{G(i)}, \lambda\right)$ into linguistic 2-tuples, denoted as $\left(s_{I^{\prime}(i)}^{n\left(t^{\prime}\right)}, \lambda^{\prime}\right)$ in $\bar{S}^{n\left(t^{\prime}\right)}$, where

$$
\begin{aligned}
\left(s_{I^{\prime}(i)}^{n\left(t^{\prime}\right)}, \lambda^{\prime}\right) & =\operatorname{TF}\left(s_{I(i)}^{G(i)}, \lambda\right) \\
& =\Delta\left(\frac{\Delta^{-1}\left(s_{I(i)}^{G(i)}, \lambda\right) \cdot\left(n\left(t^{\prime}\right)-1\right)}{G(i)-1}\right) .
\end{aligned}
$$

Then, a computational model is used over $\bar{S}^{n\left(t^{\prime}\right)}$ with a result denoted as $\left(s_{r}^{n\left(t^{\prime}\right)}, \lambda_{r}\right) \in \bar{S}^{n\left(t^{\prime}\right)}$.

(3) Retranslation process: the result $\left(s_{r}^{n\left(t^{\prime}\right)}, \lambda_{r}\right) \in \bar{S}^{n\left(t^{\prime}\right)}$ is transformed into the unbalanced term in $\bar{S}$, by using the transformation function $\psi^{-1}$; that is,

$$
\psi^{-1}: \operatorname{LH}(\bar{S}) \longrightarrow \bar{S}
$$

so that $\psi^{-1}\left(s_{r}^{n\left(t^{\prime}\right)}, \lambda_{r}\right)=\left(s_{\text {result }}, \lambda_{\text {result }}\right) \in \bar{S}$.

\section{B. Proof of Theorem 7}

Obviously, rules (1) and (2) are correct.

(3) For rule (3),

$$
\begin{aligned}
& \lambda\left(s d_{1} \oplus s d_{2}\right)=\lambda \bigcup_{\left(s_{i}, \tilde{h}_{1}, \widetilde{g}_{1}\right) \in s d_{1},\left(s_{j}, \tilde{h}_{2}, \tilde{g}_{2}\right) \in s d_{2}}\left(s_{\Delta_{t_{0}}^{-1}\left(\mathrm{TF}_{t_{0}}^{t_{i}}\left(\psi\left(s_{i}\right)\right)\right)+\Delta_{t_{0}}^{-1}\left(\mathrm{TF}_{t_{0}}^{t_{j}}\left(\psi\left(s_{j}\right)\right)\right)},\right.
\end{aligned}
$$

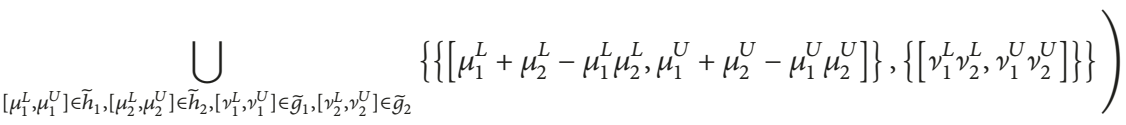

$$
\begin{aligned}
& =\bigcup_{\left(s_{i}, \widetilde{h}_{1}, \tilde{g}_{1}\right) \in s d_{1},\left(s_{j}, \tilde{h}_{2}, \tilde{g}_{2}\right) \in s d_{2}}\left(s_{\lambda\left(\Delta_{t_{0}}^{-1}\left(\operatorname{TF}_{t_{0}}^{t_{1}}\left(\psi\left(s_{i}\right)\right)\right)+\Delta_{t_{0}}^{-1}\left(\mathrm{TF}_{t_{0}}^{t_{j}}\left(\psi\left(s_{j}\right)\right)\right)\right)},\right. \\
& \left.\bigcup_{\left[\mu_{1}^{L}, \mu_{1}^{U}\right] \in \tilde{h}_{1},\left[\mu_{2}^{L}, \mu_{2}^{U}\right] \in \bar{h}_{2},\left[\nu_{1}^{L}, \nu_{1}^{U}\right] \in \tilde{g}_{1},\left[\nu_{2}^{L}, \nu_{2}\right] \in \tilde{g}_{2}}\left\{\left\{\left[1-\left(1-\left(\mu_{1}^{L}+\mu_{2}^{L}-\mu_{1}^{L} \mu_{2}^{L}\right)\right)^{\lambda}, 1-\left(1-\left(\mu_{1}^{U}+\mu_{2}^{U}-\mu_{1}^{U} \mu_{2}^{U}\right)\right)^{\lambda}\right]\right\},\left\{\left[\left(v_{1}^{L} \nu_{2}^{L}\right)^{\lambda},\left(v_{1}^{U} \nu_{2}^{U}\right)^{\lambda}\right]\right\}\right\}\right) \text {, }
\end{aligned}
$$


$\lambda s d_{1}=\bigcup_{\left(s_{i}, \widetilde{h}_{1}, \widetilde{g}_{1}\right) \in s d_{1}}\left(s_{\lambda \Delta_{t_{0}}^{-1}\left(\operatorname{TF}_{t_{0}}^{t_{i}}\left(\psi\left(s_{i}\right)\right)\right)}, \bigcup_{\left[\mu_{1}^{L}, \mu_{1}^{U}\right] \in \widetilde{h}_{1},\left[\nu_{1}^{L}, \nu_{1}^{U}\right] \in \widetilde{g}_{1}}\left\{\left\{\left[1-\left(1-\mu_{1}^{L}\right)^{\lambda}, 1-\left(1-\mu_{1}^{U}\right)^{\lambda}\right]\right\},\left\{\left[\left(v_{1}^{L}\right)^{\lambda},\left(v_{1}^{U}\right)^{\lambda}\right]\right\}\right\}\right)$,
$\lambda s d_{2}=\bigcup_{\left(s_{j}, \widetilde{h}_{2}, \widetilde{g}_{2}\right) \in s d_{2}}\left(s_{\lambda \Delta_{t_{0}}^{-1}\left(\operatorname{TF}_{t_{0}}^{t_{j}}\left(\psi\left(s_{j}\right)\right)\right)^{\prime}}, \bigcup_{\left[\mu_{2}^{L}, \mu_{2}^{U}\right] \in \widetilde{h}_{2},\left[\nu_{2}^{L}, \nu_{2}^{U}\right] \in \widetilde{g}_{2}}\left\{\left\{\left[1-\left(1-\mu_{2}^{L}\right)^{\lambda}, 1-\left(1-\mu_{2}^{U}\right)^{\lambda}\right]\right\},\left\{\left[\left(v_{2}^{L}\right)^{\lambda},\left(v_{2}^{U}\right)^{\lambda}\right]\right\}\right\}\right)$,

$\lambda s d_{1} \oplus \lambda s d_{2}=\bigcup_{\left(s_{i}, \widetilde{h}_{1}, \tilde{g}_{1}\right) \in s d_{1},\left(s_{j}, \widetilde{h}_{2}, \widetilde{g}_{2}\right) \in s d_{2}}\left(s_{\lambda\left(\Delta_{t_{0}}^{-1}\left(\mathrm{TF}_{t_{0}}^{t_{i}}\left(\psi\left(s_{i}\right)\right)\right)+\Delta_{t_{0}}^{-1}\left(\mathrm{TF}_{t_{0}}^{t_{j}}\left(\psi\left(s_{j}\right)\right)\right)\right)}\right.$,

$\left.\bigcup_{\left[\mu_{1}^{L}, \mu_{1}^{U}\right] \in \widetilde{h}_{1},\left[\mu_{2}^{L}, \mu_{2}^{U}\right] \in \widetilde{h}_{2},\left[v_{1}^{L}, v_{1}^{U}\right] \in \widetilde{g}_{1},\left[\nu_{2}^{L}, \nu_{2}^{U}\right] \in \widetilde{g}_{2}}\left\{\left\{\left[1-\left(1-\left(\mu_{1}^{L}+\mu_{2}^{L}-\mu_{1}^{L} \mu_{2}^{L}\right)\right)^{\lambda}, 1-\left(1-\left(\mu_{1}^{U}+\mu_{2}^{U}-\mu_{1}^{U} \mu_{2}^{U}\right)\right)^{\lambda}\right]\right\},\left\{\left[\left(v_{1}^{L} v_{2}^{L}\right)^{\lambda},\left(v_{1}^{U} v_{2}^{U}\right)^{\lambda}\right]\right\}\right\}\right)$

$=\lambda\left(s d_{1} \oplus s d_{2}\right) ;$

(4)

$s d_{1}^{\lambda}=\bigcup_{\left(s_{i}, \widetilde{h}_{1}, \widetilde{g}_{1}\right) \in s d_{1}}\left(s_{\left(\Delta_{t_{0}}^{-1}\left(\mathrm{TF}_{t_{0}}^{t_{i}}\left(\psi\left(s_{i}\right)\right)\right)\right)^{\lambda}}^{\lambda} \bigcup_{\left.\left[\mu_{1}^{L}, \mu_{1}^{U}\right] \in \widetilde{h}_{1}, \nu_{1}^{L}, \nu_{1}^{U}\right] \in \widetilde{g}_{1}}\left\{\left\{\left[\left(\mu_{1}^{L}\right)^{\lambda},\left(\mu_{1}^{U}\right)^{\lambda}\right]\right\},\left\{\left[1-\left(1-v_{1}^{L}\right)^{\lambda}, 1-\left(1-v_{1}^{U}\right)^{\lambda}\right]\right\}\right\}\right)$,

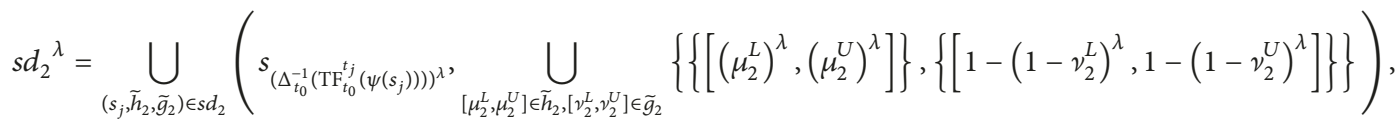

$s d_{1}^{\lambda} \otimes s d_{2}^{\lambda}=\left(s d_{1} \otimes s d_{2}\right)^{\lambda}$

$\bigcup_{\left(s_{i}, \widetilde{h}_{1}, \widetilde{g}_{1}\right) \in s d_{1},\left(s_{j}, \widetilde{h}_{2}, \widetilde{g}_{2}\right) \in s d_{2}}\left(s_{\Delta_{t_{0}}^{-1}\left(\mathrm{TF}_{t_{0}}^{t_{i}}\left(\psi\left(s_{i}\right)\right)\right) \times \Delta_{t_{0}}^{-1}\left(\operatorname{TF}_{t_{0}}^{t_{j}}\left(\psi\left(s_{j}\right)\right)\right)}\right)$

$\left.\bigcup_{\left.\left[\mu_{1}^{L}, \mu_{1}^{U}\right] \in \widetilde{h}_{1},\left[\mu_{2}^{L}, \mu_{2}^{U}\right] \in \widetilde{h}_{2}, \nu_{1}^{L}, \nu_{1}^{U}\right] \in \widetilde{g}_{1},\left[v_{2}^{L}, v_{2}^{U}\right] \in \widetilde{g}_{2}}\left\{\left\{\left[\left(\mu_{1}^{L} \mu_{2}^{L}\right)^{\lambda},\left(\mu_{1}^{U} \mu_{2}^{U}\right)^{\lambda}\right]\right\},\left\{\left[1-\left(1-\left(v_{1}^{L}+v_{2}^{L}-v_{1}^{L} \nu_{2}^{L}\right)\right)^{\lambda}, 1-\left(1-\left(v_{1}^{U}+v_{2}^{U}-v_{1}^{U} v_{2}^{U}\right)\right)^{\lambda}\right]\right\}\right\}\right) ;$

(5)

$$
\begin{aligned}
& \lambda_{1} s d=\bigcup_{\left(s_{k}, \widetilde{h}, \widetilde{g}\right) \in s d}\left(s_{\lambda_{1} \Delta_{t_{0}}^{-1}\left(\mathrm{TF}_{t_{0}}^{t_{k}}\left(\psi\left(s_{k}\right)\right)\right)^{\prime}} \bigcup_{\left[\mu^{L}, \mu^{U}\right] \in \widetilde{h},\left[\nu^{L}, \nu^{U}\right] \in \tilde{g}}\left\{\left\{\left[1-\left(1-\mu^{L}\right)^{\lambda_{1}}, 1-\left(1-\mu^{U}\right)^{\lambda_{1}}\right]\right\},\left\{\left[\left(\nu^{L}\right)^{\lambda_{1}},\left(\nu^{U}\right)^{\lambda_{1}}\right]\right\}\right\}\right), \\
& \lambda_{2} s d=\bigcup_{\left(s_{k}, \widetilde{h}, \widetilde{g}\right) \in s d}\left(s_{\lambda_{2} \Delta_{t_{0}}^{-1}\left(\mathrm{TF}_{t_{0}}^{t_{k}}\left(\psi\left(s_{k}\right)\right)\right)^{\prime}} \bigcup_{\left[\mu^{L}, \mu^{U}\right] \in \widetilde{h},\left[\nu^{L}, \nu^{U}\right] \in \tilde{g}}\left\{\left\{\left[1-\left(1-\mu^{L}\right)^{\lambda_{2}}, 1-\left(1-\mu^{U}\right)^{\lambda_{2}}\right]\right\},\left\{\left[\left(\nu^{L}\right)^{\lambda_{2}},\left(\nu^{U}\right)^{\lambda_{2}}\right]\right\}\right\}\right), \\
& \left(\lambda_{1}+\lambda_{2}\right) s d=\bigcup_{\left(s_{k}, \widetilde{h}, \widetilde{g}\right) \in s d}\left(s_{\left(\lambda_{1}+\lambda_{2}\right) \Delta_{t_{0}}^{-1}\left(\operatorname{TF}_{t_{0}}^{t_{k}}\left(\psi\left(s_{k}\right)\right)\right)},\right.
\end{aligned}
$$$$
\left.\bigcup_{\left[\mu^{L}, \mu^{U}\right] \in \widetilde{h},\left[\nu^{L}, \nu^{U}\right] \in \widetilde{g}}\left\{\left\{\left[1-\left(1-\mu^{L}\right)^{\lambda_{1}+\lambda_{2}}, 1-\left(1-\mu^{U}\right)^{\lambda_{1}+\lambda_{2}}\right]\right\},\left\{\left[\left(\nu^{L}\right)^{\lambda_{1}+\lambda_{2}},\left(\nu^{U}\right)^{\lambda_{1}+\lambda_{2}}\right]\right\}\right\}\right),
$$ 


$$
\begin{aligned}
& \lambda_{1} s d+\lambda_{2} s d=\bigcup_{\left(s_{k}, \tilde{h}, \tilde{g}\right) \in s d}\left(s_{\lambda_{1} \Delta_{t_{0}}^{-1}\left(\mathrm{TF}_{t_{0}}^{t_{k}}\left(\psi\left(s_{k}\right)\right)\right)+\lambda_{2} \Delta_{t_{0}}^{-1}\left(\mathrm{TF}_{t_{0}}^{t_{k}}\left(\psi\left(s_{k}\right)\right)\right)}\right. \\
&\left.\bigcup_{\left[\mu^{L}, \mu^{U}\right] \in \widetilde{h},\left[\nu^{L}, \nu^{U}\right] \in \tilde{g}}\left\{\left\{\left[1-\left(1-\mu^{L}\right)^{\lambda_{1}+\lambda_{2}}, 1-\left(1-\mu^{U}\right)^{\lambda_{1}+\lambda_{2}}\right]\right\},\left\{\left[\left(\nu^{L}\right)^{\lambda_{1}+\lambda_{2}},\left(\nu^{U}\right)^{\lambda_{1}+\lambda_{2}}\right]\right\}\right\}\right)=\left(\lambda_{1}+\lambda_{2}\right) s d ;
\end{aligned}
$$

(6)

$$
\begin{aligned}
& s d^{\lambda_{1}}=\bigcup_{\left(s_{k}, \widetilde{h}, \tilde{g}\right) \in s d}\left(s_{\left(\Delta_{t_{0}}^{-1}\left(\operatorname{TF}_{t_{0}}^{t_{k}}\left(\psi\left(s_{k}\right)\right)\right)\right)^{\lambda_{1}},} \bigcup_{\left[\mu^{L}, \mu^{U}\right] \in \widetilde{h},\left[\nu^{L}, \nu^{U}\right] \in \tilde{g}}\left\{\left\{\left[\left(\mu^{L}\right)^{\lambda_{1}},\left(\mu^{U}\right)^{\lambda_{1}}\right]\right\},\left\{\left[1-\left(1-\nu^{L}\right)^{\lambda_{1}}, 1-\left(1-\nu^{U}\right)^{\lambda_{1}}\right]\right\}\right\}\right), \\
& s d^{\lambda_{2}}=\bigcup_{\left(s_{k}, \widetilde{h}, \tilde{g}\right) \in s d}\left(s_{\left(\Delta_{t_{0}}^{-1}\left(\operatorname{TF}_{t_{0}}^{t_{k}}\left(\psi\left(s_{k}\right)\right)\right)\right)^{\lambda_{2}},} \bigcup_{\left[\mu^{L}, \mu^{U}\right] \in \widetilde{h},\left[\nu^{L}, \nu^{U}\right] \in \tilde{g}}\left\{\left\{\left[\left(\mu^{L}\right)^{\lambda_{2}},\left(\mu^{U}\right)^{\lambda_{2}}\right]\right\},\left\{\left[1-\left(1-\nu^{L}\right)^{\lambda_{2}}, 1-\left(1-\nu^{U}\right)^{\lambda_{2}}\right]\right\}\right\}\right), \\
& s d^{\lambda_{1}+\lambda_{2}}=\bigcup_{\left(s_{k}, \widetilde{h}, \tilde{g}\right) \in s d}\left(s_{\left(\Delta_{t_{0}}^{-1}\left(\operatorname{TF}_{t_{0}}^{t_{k}}\left(\psi\left(s_{k}\right)\right)\right)\right)^{\lambda_{1}+\lambda_{2}},}\right. \\
& \left.\bigcup_{\left[\mu^{L}, \mu^{U}\right] \in \widetilde{h},\left[\nu^{L}, \nu^{U}\right] \in \tilde{g}}\left\{\left\{\left[\left(\mu^{L}\right)^{\lambda_{1}+\lambda_{2}},\left(\mu^{U}\right)^{\lambda_{1}+\lambda_{2}}\right]\right\},\left\{\left[1-\left(1-\nu^{L}\right)^{\lambda_{1}+\lambda_{2}}, 1-\left(1-\nu^{U}\right)^{\lambda_{1}+\lambda_{2}}\right]\right\}\right\}\right)=s d^{\lambda_{1}} \otimes s d^{\lambda_{2}} .
\end{aligned}
$$

\section{Proof of Theorem 15}

(1) When $n=1$, obviously, it is right.

$$
\begin{gathered}
\text { W-IVDhFuBL-PA }(s d)=\bigcup_{\left(s_{0}, \widetilde{h}, \tilde{g}\right) \in s d}\left(s_{\Delta_{t_{0}}^{-1}\left(\mathrm{TT}_{t_{0}}^{t_{0}}\left(\psi\left(s_{0}\right)\right)\right)}\right. \\
\left.\bigcup_{\left[\mu^{L}, \mu^{U}\right] \in \widetilde{h},\left[\nu^{L}, \nu^{U}\right] \in \tilde{g}}\left\{\left\{\left[\mu^{L}, \mu^{U}\right]\right\},\left\{\left[\nu^{L}, \nu^{U}\right]\right\}\right\}\right) .
\end{gathered}
$$$$
\text { (2) When } n=2 \text {, }
$$$$
\frac{\omega_{1}\left(1+T\left(s d_{1}\right)\right)}{\sum_{i=1}^{2} \omega_{i}\left(1+T\left(s d_{i}\right)\right)} s d_{1}
$$

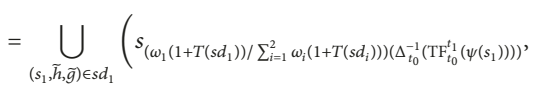

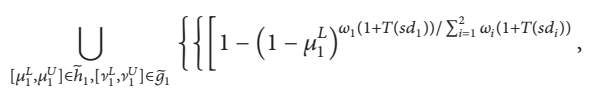$$
\left.\left.1-\left(1-\mu_{1}^{U}\right)^{\omega_{1}\left(1+T\left(s d_{1}\right)\right) / \sum_{i=1}^{2} \omega_{i}\left(1+T\left(s d_{i}\right)\right)}\right]\right\},
$$$$
\left\{\left[\left(v_{1}^{L}\right)^{\omega_{1}\left(1+T\left(s d_{1}\right)\right) / \sum_{i=1}^{2} \omega_{i}\left(1+T\left(s d_{i}\right)\right)},\right.\right.
$$$$
\left.\left.\left.\left.\left(\nu_{1}^{U}\right)^{\omega_{1}\left(1+T\left(s d_{1}\right)\right) / \Sigma_{i=1}^{2} \omega_{i}\left(1+T\left(s d_{i}\right)\right)}\right]\right\}\right\}\right),
$$

(C.1)

$$
\begin{aligned}
& \frac{\omega_{2}\left(1+T\left(s d_{2}\right)\right)}{\sum_{i=1}^{2} \omega_{i}\left(1+T\left(s d_{i}\right)\right)} s d_{2}
\end{aligned}
$$

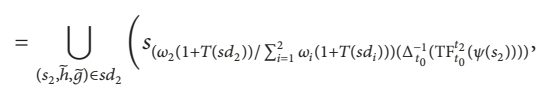

$$
\begin{aligned}
& \bigcup_{\left[\mu_{2}^{L}, \mu_{2}^{U}\right] \in \bar{h}_{2},\left\{v_{2}^{2}, \nu_{2}^{U}\right] \in \bar{g}_{2}}\left\{\left\{\left[1-\left(1-\mu_{2}^{L}\right)^{\left.\omega_{2}\left(1+T\left(s d_{2}\right)\right)\right) \Sigma_{i=1}^{2} \omega_{i}\left(1+T\left(s d_{1}\right)\right)},\right.\right.\right. \\
& \left.\left.1-\left(1-\mu_{2}^{U}\right)^{\omega_{2}\left(1+T\left(s d_{2}\right)\right) / \sum_{i=1}^{2} \omega_{i}\left(1+T\left(s d_{i}\right)\right)}\right]\right\}, \\
& \left.\left.\left\{\left[\left(v_{2}^{L}\right)^{\omega_{2}\left(1+T\left(s_{2}\right)\right) / \sum_{i=1}^{2} \omega_{i}\left(1+T\left(s d_{i}\right)\right)},\left(v_{2}^{V}\right)^{\omega_{2}\left(1+T\left(\left(s_{2}\right)\right)\right) / \sum_{i=1}^{2} \omega_{i}\left(1+T\left(s d_{i}\right)\right)}\right]\right\}\right\}\right), \\
& \frac{\omega_{1}\left(1+T\left(s d_{1}\right)\right)}{\sum_{i=1}^{2} \omega_{i}\left(1+T\left(s d_{i}\right)\right)} s d_{1} \\
& +\frac{\omega_{2}\left(1+T\left(s d_{2}\right)\right)}{\sum_{i=1}^{2} \omega_{i}\left(1+T\left(s d_{i}\right)\right)} s d_{2}
\end{aligned}
$$

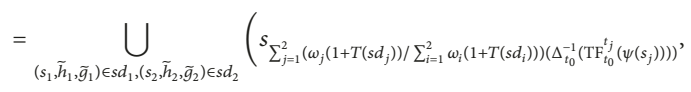

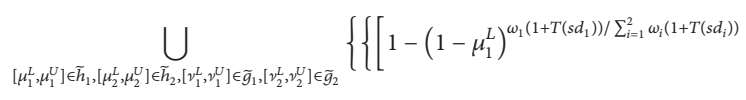

$$
\begin{aligned}
& \cdot\left(1-\mu_{2}^{L}\right)^{\omega_{2}\left(1+T\left(s d_{2}\right)\right) / \sum_{i=1}^{2} \omega_{i}\left(1+T\left(s d_{i}\right)\right)}, \\
& \left.\left.1-\left(1-\mu_{1}^{U}\right)^{\omega_{1}\left(1+T\left(s d_{1}\right)\right) / \sum_{i=1}^{2} \omega_{i}\left(1+T\left(s d_{i}\right)\right)}\left(1-\mu_{2}^{U}\right)^{\omega_{2}\left(1+T\left(s d_{2}\right)\right) / \sum_{i=1}^{2} \omega_{i}\left(1+T\left(s d_{i}\right)\right)}\right]\right\},
\end{aligned}
$$




$$
\begin{aligned}
& \left\{\left[\left(\nu_{1}^{L}\right)^{\omega_{1}\left(1+T\left(s d_{1}\right)\right) / \sum_{i=1}^{2} \omega_{i}\left(1+T\left(s d_{i}\right)\right)}\left(\nu_{2}^{L}\right)^{\omega_{2}\left(1+T\left(s d_{2}\right)\right) / \sum_{i=1}^{2} \omega_{i}\left(1+T\left(s d_{i}\right)\right)},\right.\right. \\
& \left.\left.\left.\left.\left(\nu_{1}^{U}\right)^{\omega_{1}\left(1+T\left(s d_{1}\right)\right) / \sum_{i=1}^{2} \omega_{i}\left(1+T\left(s d_{i}\right)\right)}\left(\nu_{2}^{U}\right)^{\omega_{2}\left(1+T\left(s d_{2}\right)\right) / \sum_{i=1}^{2} \omega_{i}\left(1+T\left(s d_{i}\right)\right)}\right]\right\}\right\}\right) ;
\end{aligned}
$$

so when $n=2$, Theorem 15 also is right.

(3) Suppose when $n=k$, Theorem 15 is right; then we have

W-IVDHFUL-PA $\left(s d_{1}, s d_{2}, \ldots, s d_{k}\right)$

$$
=\bigcup_{\left(s_{j}, \widetilde{h}_{j}, \widetilde{g}_{j}\right) \in s d_{j}}\left(s_{\sum_{j=1}^{k}\left(\omega_{j}\left(1+T\left(s d_{j}\right)\right) / \sum_{i=1}^{n} \omega_{j}\left(1+T\left(s d_{i}\right)\right)\right) \Delta_{t_{0}}^{-1}\left(\mathrm{TF}_{t_{0}}^{t_{j}}\left(\psi\left(s_{j}\right)\right)\right)},\right.
$$$$
\bigcup_{\left[\mu_{j}^{L}, \mu_{j}^{U}\right] \in \widetilde{h}_{j},\left[\nu_{j}^{L}, \nu_{j}^{U}\right] \in \widetilde{g}_{j}}\left\{\left\{\left[1-\prod_{j=1}^{k}\left(1-\mu_{j}^{L}\right)^{\omega_{j}\left(1+T\left(s d_{j}\right)\right) / \sum_{i=1}^{n} \omega_{j}\left(1+T\left(s d_{i}\right)\right)}\right.\right.\right.
$$$$
\left.\left.1-\prod_{j=1}^{k}\left(1-\mu_{j}^{U}\right)^{\omega_{j}\left(1+T\left(s d_{j}\right)\right) / \sum_{i=1}^{n} \omega_{j}\left(1+T\left(s d_{i}\right)\right)}\right]\right\},
$$

$$
\begin{aligned}
& \left\{\left[\prod_{j=1}^{k}\left(v_{j}^{L}\right)^{\omega_{j}\left(1+T\left(s d_{j}\right)\right) / \sum_{i=1}^{n} \omega_{j}\left(1+T\left(s d_{i}\right)\right)},\right.\right. \\
& \left.\left.\left.\left.\prod_{j=1}^{k}\left(v_{j}^{U}\right)^{\omega_{j}\left(1+T\left(s d_{j}\right)\right) / \sum_{i=1}^{n} \omega_{j}\left(1+T\left(s d_{i}\right)\right)}\right]\right\}\right\}\right) .
\end{aligned}
$$

Then when $n=k+1$,

$\mathrm{W}-\mathrm{IVDHFUBL-PA}\left(s d_{1}, s d_{2}, \ldots, s d_{k}, s d_{k+1}\right)$

$$
\begin{aligned}
& =\left(\bigoplus_{j=1}^{k} \frac{\omega_{j}\left(1+T\left(s d_{j}\right)\right)}{\sum_{i=1}^{n} \omega_{i}\left(1+T\left(s d_{i}\right)\right)} s d_{j}\right) \oplus \frac{\omega_{k+1}\left(1+T\left(s d_{k+1}\right)\right)}{\sum_{i=1}^{n} \omega_{i}\left(1+T\left(s d_{i}\right)\right)} s d_{k+1} \\
& =\bigcup_{\left(s_{j}, \widetilde{h}_{j}, \widetilde{g}_{j}\right) \in s d_{j}}\left(s_{\sum_{j=1}^{k+1}\left(\omega_{j}\left(1+T\left(s d_{j}\right)\right) / \sum_{i=1}^{n} \omega_{i}\left(1+T\left(s d_{i}\right)\right)\right) \Delta_{t_{0}}^{-1}\left(\operatorname{TF}_{t_{0}}^{t_{j}}\left(\psi\left(s_{j}\right)\right)\right)},\right. \\
& \bigcup_{\left[\mu_{j}^{L}, \mu_{j}^{U}\right] \in \widetilde{h}_{j},\left[\nu_{j}^{L}, \nu_{j}^{U}\right] \in \widetilde{g}_{j}}\left\{\left\{\left[1-\prod_{j=1}^{k+1}\left(1-\mu_{j}^{L}\right)^{\omega_{j}\left(1+T\left(s d_{j}\right)\right) / \sum_{i=1}^{n} \omega_{i}\left(1+T\left(s d_{i}\right)\right)},\right.\right.\right. \\
& \left.\left.1-\prod_{j=1}^{k+1}\left(1-\mu_{j}^{U}\right)^{\omega_{j}\left(1+T\left(s d_{j}\right)\right) / \sum_{i=1}^{n} \omega_{i}\left(1+T\left(s d_{i}\right)\right)}\right]\right\}, \\
& \left\{\left[\prod_{j=1}^{k+1}\left(v_{j}^{L}\right)^{\omega_{j}\left(1+T\left(s d_{j}\right)\right) / \sum_{i=1}^{n} \omega_{i}\left(1+T\left(s d_{i}\right)\right)},\right.\right. \\
& \left.\left.\left.\left.\prod_{j=1}^{k+1}\left(v_{j}^{U}\right)^{\omega_{j}\left(1+T\left(s d_{j}\right)\right) / \sum_{i=1}^{n} \omega_{i}\left(1+T\left(s d_{i}\right)\right)}\right]\right\}\right\}\right) .
\end{aligned}
$$

So, when $n=k+1$, Theorem 15 is right too.

According to steps (1), (2), and (3), we can conclude that Theorem 15 is right for all $n$.

\section{Proof of Theorem 16}

(1) Since $s d_{j}=s d$ for all $j=1,2, \ldots, n$, then

W-IVDHFUBL-PA $\left(s d_{1}, s d_{2}, \ldots, s d_{n}\right)$

$$
=\bigcup_{\left(s_{0}, \widetilde{h}_{j}, \widetilde{g}_{j}\right) \in s d}\left(s_{0}\right.
$$

$$
\left.\bigcup_{\left[\mu^{L}, \mu^{U}\right] \in \tilde{h},\left[\nu^{L}, \nu^{U}\right] \in \tilde{g}}\left\{\left\{\left[\mu^{L}, \mu^{U}\right]\right\},\left\{\left[\nu^{L}, \nu^{U}\right]\right\}\right\}\right)=s d .
$$

(2) Suppose $s d^{-}=\left(s_{0}^{-}, \widetilde{h}^{-}, \widetilde{g}\right), s d^{+}=\left(s_{0}^{+}, \widetilde{h}^{+}, \widetilde{g}^{+}\right)$, where

$$
\begin{aligned}
& s_{0}^{-}=\min _{j}\left(s_{\Delta_{t_{0}}^{-1}\left(\operatorname{TF}_{t_{0}}^{t_{j}}\left(\psi\left(s_{j}\right)\right)\right)}\right), \\
& s_{0}^{+}=\max _{j}\left(s_{\Delta_{t_{0}}^{-1}\left(\operatorname{TF}_{t_{0}}^{t_{j}}\left(\psi\left(s_{j}\right)\right)\right)}\right), \\
& \tilde{h}^{-}=\bigcup_{\left[\mu_{j}^{L}, \mu_{j}^{U}\right] \in \tilde{h}_{j}}\left\{\left[\mu^{L-}, \mu^{U-}\right]\right\} \\
& =\bigcup_{\left[\mu_{j}^{L}, \mu_{j}^{U}\right] \in \tilde{h}_{j}}\left\{\left[\min _{1 \leq j \leq n} \mu_{j}^{L}, \min _{1 \leq j \leq n} \mu_{j}^{U}\right]\right\}, \\
& \widetilde{h}^{+}=\bigcup_{\left[\mu_{j}^{L}, \mu_{j}^{U}\right] \in \tilde{h}_{j}}\left\{\left[\mu^{L+}, \mu^{U+}\right]\right\} \\
& =\bigcup_{\left[\mu_{j}^{L}, \mu_{j}^{U}\right] \in \tilde{h}_{j}}\left\{\left[\max _{1 \leq j \leq n} \mu_{j}^{L}, \max _{1 \leq j \leq n} \mu_{j}^{U}\right]\right\}, \\
& \widetilde{\mathfrak{g}}^{-}=\bigcup_{\left[\nu_{j}^{L}, \nu_{j}^{U}\right] \in \widetilde{g}_{j}}\left\{\left[\nu^{L-}, \nu^{U-}\right]\right\} \\
& =\bigcup_{\left[\nu_{j}^{L}, \nu_{j}^{U}\right] \in \tilde{g}_{j}}\left\{\left[\max _{1 \leq j \leq n} v_{j}^{L}, \max _{1 \leq j \leq n} \nu_{j}^{U}\right]\right\}, \\
& \tilde{g}^{+}=\bigcup_{\left[\nu_{j}^{L}, \nu_{j}^{U}\right] \in \widetilde{g}_{j}}\left\{\left[\nu^{L+}, \nu^{U+}\right]\right\} \\
& =\bigcup_{\left[\nu_{j}^{L}, v_{j}^{U}\right] \in \tilde{g}_{j}}\left\{\left[\min _{1 \leq j \leq n} v_{j}^{L}, \min _{1 \leq j \leq n} v_{j}^{U}\right]\right\} .
\end{aligned}
$$

Obviously,

$$
\begin{aligned}
s_{0}^{-} & =\min _{j}\left(s_{\Delta_{t_{0}}^{-1}\left(\operatorname{TF}_{t_{0}}^{t_{j}}\left(\psi\left(s_{j}\right)\right)\right)}\right) \\
& \leq s_{\sum_{j=1}^{n}\left(\omega_{j}\left(1+T\left(s d_{j}\right)\right) / \sum_{i=1}^{n} \omega_{i}\left(1+T\left(s d_{i}\right)\right)\right) \Delta_{t_{0}}^{-1}\left(\operatorname{TF}_{t_{0}}^{t_{j}}\left(\psi\left(s_{j}\right)\right)\right)} \\
& \leq \max _{j}\left(s_{\Delta_{t_{0}}^{-1}\left(\mathrm{TF}_{t_{0}}^{t_{j}}\left(\psi\left(s_{j}\right)\right)\right)}\right)=s_{0}^{+} .
\end{aligned}
$$


And for all $j=1,2, \ldots, n$, we have

$$
\begin{aligned}
& \left(1-\prod_{j=1}^{n}\left(1-\mu^{L+}\right)^{\omega_{j}\left(1+T\left(s d_{j}\right)\right) / \sum_{i=1}^{n} \omega_{i}\left(1+T\left(s d_{i}\right)\right)}\right) \\
& +\left(1-\prod_{j=1}^{n}\left(1-\mu^{U+}\right)^{\omega_{j}\left(1+T\left(s d_{j}\right)\right) / \sum_{i=1}^{n} \omega_{i}\left(1+T\left(s d_{i}\right)\right)}\right) \\
& \quad\left(1-\prod_{j=1}^{n}\left(1-\mu_{j}^{L}\right)^{\omega_{j}\left(1+T\left(s d_{j}\right)\right) / \sum_{i=1}^{n} \omega_{i}\left(1+T\left(s d_{i}\right)\right)}\right) \\
& +\left(1-\prod_{j=1}^{n}\left(1-\mu_{j}^{U}\right)^{\omega_{j}\left(1+T\left(s d_{j}\right)\right) / \sum_{i=1}^{n} \omega_{i}\left(1+T\left(s d_{i}\right)\right)}\right) \\
& \geq\left(1-\prod_{j=1}^{n}\left(1-\mu^{L-}\right)^{\omega_{j}\left(1+T\left(s d_{j}\right)\right) / \sum_{i=1}^{n} \omega_{i}\left(1+T\left(s d_{i}\right)\right)}\right) \\
& +\left(1-\prod_{j=1}^{n}\left(1-\mu^{U-}\right)^{\omega_{j}\left(1+T\left(s d_{j}\right)\right) / \sum_{i=1}^{n} \omega_{i}\left(1+T\left(s d_{i}\right)\right)}\right) .
\end{aligned}
$$

Meanwhile, we have

$$
\begin{aligned}
& \left(\prod_{j=1}^{n}\left(\nu^{L-}\right)^{\omega_{j}\left(1+T\left(s d_{j}\right)\right) / \sum_{i=1}^{n} \omega_{i}\left(1+T\left(s d_{i}\right)\right)}\right) \\
& +\left(\prod_{j=1}^{n}\left(\nu^{U-}\right)^{\omega_{j}\left(1+T\left(s d_{j}\right)\right) / \sum_{i=1}^{n} \omega_{i}\left(1+T\left(s d_{i}\right)\right)}\right) \\
& \geq\left(\prod_{j=1}^{n}\left(\nu^{L}\right)^{\omega_{j}\left(1+T\left(s d_{j}\right)\right) / \sum_{i=1}^{n} \omega_{i}\left(1+T\left(s d_{i}\right)\right)}\right) \\
& +\left(\prod_{j=1}^{n}\left(\nu^{U}\right)^{\omega_{j}\left(1+T\left(s d_{j}\right)\right) / \sum_{i=1}^{n} \omega_{i}\left(1+T\left(s d_{i}\right)\right)}\right) \\
& \quad \geq\left(\prod_{j=1}^{n}\left(\nu^{L+}\right)^{\omega_{j}\left(1+T\left(s d_{j}\right)\right) / \sum_{i=1}^{n} \omega_{i}\left(1+T\left(s d_{i}\right)\right)}\right) \\
& \quad+\left(\prod_{j=1}^{n}\left(\nu^{U+}\right)^{\omega_{j}\left(1+T\left(s d_{j}\right)\right) / \sum_{i=1}^{n} \omega_{i}\left(1+T\left(s d_{i}\right)\right)}\right) .
\end{aligned}
$$

Then

$$
\begin{aligned}
& \left(1-\prod_{j=1}^{n}\left(1-\mu^{L+}\right)^{\omega_{j}\left(1+T\left(s d_{j}\right)\right) / \sum_{i=1}^{n} \omega_{i}\left(1+T\left(s d_{i}\right)\right)}\right) \\
& \quad+\left(1-\prod_{j=1}^{n}\left(1-\mu^{U+}\right)^{\omega_{j}\left(1+T\left(s d_{j}\right)\right) / \sum_{i=1}^{n} \omega_{i}\left(1+T\left(s d_{i}\right)\right)}\right) \\
& \quad-\left(\prod_{j=1}^{n}\left(v^{L+}\right)^{\omega_{j}\left(1+T\left(s d_{j}\right)\right) / \sum_{i=1}^{n} \omega_{i}\left(1+T\left(s d_{i}\right)\right)}\right)
\end{aligned}
$$

$$
\begin{aligned}
& -\left(\prod_{j=1}^{n}\left(\nu^{U+}\right)^{\omega_{j}\left(1+T\left(s d_{j}\right)\right) / \sum_{i=1}^{n} \omega_{i}\left(1+T\left(s d_{i}\right)\right)}\right) \\
& \geq\left(1-\prod_{j=1}^{n}\left(1-\mu_{j}^{L}\right)^{\omega_{j}\left(1+T\left(s d_{j}\right)\right) / \sum_{i=1}^{n} \omega_{i}\left(1+T\left(s d_{i}\right)\right)}\right) \\
& +\left(1-\prod_{j=1}^{n}\left(1-\mu_{j}^{U}\right)^{\omega_{j}\left(1+T\left(s d_{j}\right)\right) / \sum_{i=1}^{n} \omega_{i}\left(1+T\left(s d_{i}\right)\right)}\right) \\
& -\left(\prod_{j=1}^{n}\left(v^{L}\right)^{\omega_{j}\left(1+T\left(s d_{j}\right)\right) / \sum_{i=1}^{n} \omega_{i}\left(1+T\left(s d_{i}\right)\right)}\right) \\
& -\left(\prod_{j=1}^{n}\left(\nu^{U}\right)^{\omega_{j}\left(1+T\left(s d_{j}\right)\right) / \sum_{i=1}^{n} \omega_{i}\left(1+T\left(s d_{i}\right)\right)}\right) \\
& +\left(\prod_{j=1}^{n}\left(\nu^{L-}\right)^{\omega_{j}\left(1+T\left(s d_{j}\right)\right) / \sum_{i=1}^{n} \omega_{i}\left(1+T\left(s d_{i}\right)\right)}\right) \\
& +\left(1-\prod_{j=1}^{n}\left(1-\mu^{L-}\right)^{\omega_{j}\left(1+T\left(s d_{j}\right)\right) / \sum_{i=1}^{n} \omega_{i}\left(1+T\left(s d_{i}\right)\right)}\right) \\
& \left.+\prod_{j=1}^{n}\left(1-\mu^{U-}\right)^{\omega_{j}\left(1+T\left(s d_{j}\right)\right) / \sum_{i=1}^{n} \omega_{i}\left(1+T\left(s d_{j}\right)\right) / \sum_{i=1}^{n} \omega_{i}\left(1+T\left(s d_{i}\right)\right)}\right)
\end{aligned}
$$

According to Definitions 8 and 10 and Theorem 15, we have

$$
s d^{-} \leq \mathrm{W}-\mathrm{IVDHFUBL}-\mathrm{PA}\left(s d_{1}, s d_{2}, \ldots, s d_{n}\right) \leq s d^{+},
$$

which completes the proof.

\section{E. Proof of Theorem 19}

(1) Assume that $\left(s d_{1}{ }^{*}, s d_{2}{ }^{*}, \ldots, s d_{n}{ }^{*}\right)$ is any permutation of $\left(s d_{1}, s d_{2}, \ldots, s d_{n}\right)$; then for each $s d_{j}$, there exists one and only one $s d_{k}{ }^{*}$ such that $s d_{k}{ }^{*}=s d_{j}$ and vice versa. And, also we have $T\left(s d_{j}\right)=T\left(s d_{k}{ }^{*}\right)$. Thus, based on Theorem 18, we have

$$
\begin{aligned}
& \operatorname{IVDHFUBL-PA}\left(s d_{1}, s d_{2}, \ldots, s d_{n}\right) \\
& =\frac{\bigoplus_{j=1}^{n}\left(\left(1+T\left(s d_{j}\right)\right) s d_{j}\right)}{\sum_{i=1}^{n}\left(1+T\left(s d_{i}\right)\right)} \\
& =\frac{\bigoplus_{j=1}^{n}\left(\left(1+T\left(s d_{k}{ }^{*}\right)\right) s d_{k}{ }^{*}\right)}{\sum_{i=1}^{n}\left(1+T\left(s d_{i}\right)\right)} \\
& =\operatorname{IVDHFUL-PA}\left(s d_{1}{ }^{*}, s d_{2}{ }^{*}, \ldots, s d_{n}{ }^{*}\right) .
\end{aligned}
$$


(2) Since $s d_{j}=s d$ for all $j=1,2, \ldots, n$, then

$\operatorname{IVDHFUBL-PA}\left(s d_{1}, s d_{2}, \ldots, s d_{n}\right)$

$=\bigcup_{\left(s_{0}, \widetilde{h}_{j}, \widetilde{g}_{j}\right) \in s d}\left(s_{0}\right.$

$$
\left.\bigcup_{\left[\mu^{L}, \mu^{U}\right] \in \widetilde{h},\left[\nu^{L}, \nu^{U}\right] \in \tilde{g}}\left\{\left\{\left[\mu^{L}, \mu^{U}\right]\right\},\left\{\left[\nu^{L}, \nu^{U}\right]\right\}\right\}\right)=s d .
$$

(3) Suppose $s d^{-}=\left(s_{0}^{-}, \tilde{h}^{-}, \widetilde{g}\right), s d^{+}=\left(s_{0}^{+}, \tilde{h}^{+}, \widetilde{g}^{+}\right)$, where

$$
\begin{aligned}
& s_{0}^{-}=\min _{j}\left(s_{\Delta_{t_{0}}^{-1}\left(\mathrm{TF}_{t_{0}}^{t_{j}}\left(\psi\left(s_{j}\right)\right)\right)}\right), \\
& s_{0}^{+}=\max _{j}\left(s_{\Delta_{t_{0}}^{-1}\left(\operatorname{TF}_{t_{0}}^{t_{j}}\left(\psi\left(s_{j}\right)\right)\right)}\right), \\
& \tilde{h}^{-}=\bigcup_{\left[\mu_{j}^{L}, \mu_{j}^{U}\right] \in \tilde{h}_{j}}\left\{\left[\mu^{L-}, \mu^{U-}\right]\right\} \\
& =\bigcup_{\left[\mu_{j}^{L}, \mu_{j}^{U}\right] \in \tilde{h}_{j}}\left\{\left[\min _{1 \leq j \leq n} \mu_{j}^{L}, \min _{1 \leq j \leq n} \mu_{j}^{U}\right]\right\}, \\
& \tilde{h}^{+}=\bigcup_{\left[\mu_{j}^{L}, \mu_{j}^{U}\right] \in \tilde{h}_{j}}\left\{\left[\mu^{L+}, \mu^{U+}\right]\right\} \\
& =\bigcup_{\left[\mu_{j}^{L}, \mu_{j}^{U}\right] \in \tilde{h}_{j}}\left\{\left[\max _{1 \leq j \leq n} \mu_{j}^{L}, \max _{1 \leq j \leq n} \mu_{j}^{U}\right]\right\}, \\
& \widetilde{\mathfrak{g}}^{-}=\bigcup_{\left[\nu_{j}^{L}, \nu_{j}^{U}\right] \in \tilde{g}_{j}}\left\{\left[\nu^{L-}, \nu^{U-}\right]\right\} \\
& =\bigcup_{\left[\nu_{j}^{L}, v_{j}^{U}\right] \in \widetilde{g}_{j}}\left\{\left[\max _{1 \leq j \leq n} \nu_{j}^{L}, \max _{1 \leq j \leq n} \nu_{j}^{U}\right]\right\}, \\
& \widetilde{\mathfrak{g}}^{+}=\bigcup_{\left[\nu_{j}^{L}, \nu_{j}^{U}\right] \in \tilde{g}_{j}}\left\{\left[\nu^{L+}, \nu^{U+}\right]\right\} \\
& =\bigcup_{\left[v_{j}^{L}, v_{j}^{U}\right] \in \widetilde{g}_{j}}\left\{\left[\min _{1 \leq j \leq n} v_{j}^{L}, \min _{1 \leq j \leq n} v_{j}^{U}\right]\right\} .
\end{aligned}
$$

Obviously,

$$
\begin{aligned}
s_{0}^{-} & =\min _{j}\left(s_{\Delta_{t_{0}}^{-1}\left(\mathrm{TF}_{t_{0}}^{t_{j}}\left(\psi\left(s_{j}\right)\right)\right)}\right) \\
& \leq s_{\sum_{j=1}^{n}\left(\left(1+T\left(s d_{j}\right)\right) / \sum_{i=1}^{n}\left(1+T\left(s d_{i}\right)\right)\right) \Delta_{t_{0}}^{-1}\left(\operatorname{TF}_{t_{0}}^{t_{j}}\left(\psi\left(s_{j}\right)\right)\right)} \\
& \leq \max _{j}\left(s_{\Delta_{t_{0}}^{-1}\left(\operatorname{TF}_{t_{0}}^{t_{j}}\left(\psi\left(s_{j}\right)\right)\right)}\right)=s_{0}^{+} .
\end{aligned}
$$

And for all $j=1,2, \ldots, n$, we have

$$
\begin{aligned}
& \left(1-\prod_{j=1}^{n}\left(1-\mu^{L+}\right)^{\left(1+T\left(s d_{j}\right)\right) / \sum_{i=1}^{n}\left(1+T\left(s d_{i}\right)\right)}\right) \\
& +\left(1-\prod_{j=1}^{n}\left(1-\mu^{U+}\right)^{\left(1+T\left(s d_{j}\right)\right) / \sum_{i=1}^{n}\left(1+T\left(s d_{i}\right)\right)}\right) \\
& \geq\left(1-\prod_{j=1}^{n}\left(1-\mu_{j}^{L}\right)^{\left(1+T\left(s d_{j}\right)\right) / \sum_{i=1}^{n}\left(1+T\left(s d_{i}\right)\right)}\right) \\
& +\left(1-\prod_{j=1}^{n}\left(1-\mu_{j}^{U}\right)^{\left(1+T\left(s d_{j}\right)\right) / \sum_{i=1}^{n}\left(1+T\left(s d_{i}\right)\right)}\right) \\
& \geq\left(1-\prod_{j=1}^{n}\left(1-\mu^{L-}\right)^{\left(1+T\left(s d_{j}\right)\right) / \sum_{i=1}^{n}\left(1+T\left(s d_{i}\right)\right)}\right) \\
& +\left(1-\prod_{j=1}^{n}\left(1-\mu^{U-}\right)^{\left(1+T\left(s d_{j}\right)\right) / \sum_{i=1}^{n}\left(1+T\left(s d_{i}\right)\right)}\right) .
\end{aligned}
$$

Meanwhile, we have

$$
\begin{aligned}
& \left(\prod_{j=1}^{n}\left(\nu^{L-}\right)^{\left(1+T\left(s d_{j}\right)\right) / \sum_{i=1}^{n}\left(1+T\left(s d_{i}\right)\right)}\right) \\
& +\left(\prod_{j=1}^{n}\left(\nu^{U-}\right)^{\left(1+T\left(s d_{j}\right)\right) / \sum_{i=1}^{n}\left(1+T\left(s d_{i}\right)\right)}\right) \\
& \geq\left(\prod_{j=1}^{n}\left(\nu^{L}\right)^{\left(1+T\left(s d_{j}\right)\right) / \sum_{i=1}^{n}\left(1+T\left(s d_{i}\right)\right)}\right) \\
& +\left(\prod_{j=1}^{n}\left(\nu^{U}\right)^{\left(1+T\left(s d_{j}\right)\right) / \sum_{i=1}^{n}\left(1+T\left(s d_{i}\right)\right)}\right) \\
& \geq\left(\prod_{j=1}^{n}\left(\nu^{L+}\right)^{\left(1+T\left(s d_{j}\right)\right) / \sum_{i=1}^{n}\left(1+T\left(s d_{i}\right)\right)}\right) \\
& +\left(\prod_{j=1}^{n}\left(\nu^{U+}\right)^{\left(1+T\left(s d_{j}\right)\right) / \sum_{i=1}^{n}\left(1+T\left(s d_{i}\right)\right)}\right) .
\end{aligned}
$$

Then

$$
\begin{aligned}
& \left(1-\prod_{j=1}^{n}\left(1-\mu^{L+}\right)^{\left(1+T\left(s d_{j}\right)\right) / \sum_{i=1}^{n}\left(1+T\left(s d_{i}\right)\right)}\right) \\
& +\left(1-\prod_{j=1}^{n}\left(1-\mu^{U+}\right)^{\left(1+T\left(s d_{j}\right)\right) / \sum_{i=1}^{n}\left(1+T\left(s d_{i}\right)\right)}\right) \\
& \quad-\left(\prod_{j=1}^{n}\left(\nu^{L+}\right)^{\left(1+T\left(s d_{j}\right)\right) / \sum_{i=1}^{n}\left(1+T\left(s d_{i}\right)\right)}\right)
\end{aligned}
$$




$$
\begin{aligned}
& -\left(\prod_{j=1}^{n}\left(\nu^{U+}\right)^{\left(1+T\left(s d_{j}\right)\right) / \sum_{i=1}^{n}\left(1+T\left(s d_{i}\right)\right)}\right) \\
& \geq\left(1-\prod_{j=1}^{n}\left(1-\mu_{j}^{L}\right)^{\left(1+T\left(s d_{j}\right)\right) / \sum_{i=1}^{n}\left(1+T\left(s d_{i}\right)\right)}\right) \\
& +\left(1-\prod_{j=1}^{n}\left(1-\mu_{j}^{U}\right)^{\left(1+T\left(s d_{j}\right)\right) / \sum_{i=1}^{n}\left(1+T\left(s d_{i}\right)\right)}\right) \\
& -\left(\prod_{j=1}^{n}\left(v^{L}\right)^{\left(1+T\left(s d_{j}\right)\right) / \sum_{i=1}^{n}\left(1+T\left(s d_{i}\right)\right)}\right) \\
& -\left(\prod_{j=1}^{n}\left(\nu^{U}\right)^{\left(1+T\left(s d_{j}\right)\right) / \sum_{i=1}^{n}\left(1+T\left(s d_{i}\right)\right)}\right) \\
& -\left(\prod_{j=1}^{n}\left(\nu^{U-}\right)^{\left(1+T\left(s d_{j}\right)\right) / \sum_{i=1}^{n}\left(1+T\left(s d_{i}\right)\right)}\right) . \\
& +\left(1-\prod_{j=1}^{n}\left(1-\mu^{L-}\right)^{\left(1+T\left(s d_{j}\right)\right) / \sum_{i=1}^{n}\left(1+T\left(s d_{i}\right)\right)}\right) \\
& \left.+\prod_{j=1}^{n}\left(1-\mu^{U-}\right)^{\left(1+T\left(s d_{j}\right)\right) / \sum_{i=1}^{n}\left(1+T\left(s d_{i}\right)\right)}\right)
\end{aligned}
$$
have

According to Definitions 8 and 10 and Theorem 18, we

$s d^{-} \leq \operatorname{IVDHFUBL-PA}\left(s d_{1}, s d_{2}, \ldots, s d_{n}\right) \leq s d^{+}$,

which completes the proof.

\section{Conflicts of Interest}

The authors declare that there are no conflicts of interest regarding the publication of this paper.

\section{Acknowledgments}

The authors would like to greatly thank joint-support by the National Natural Science Foundation of China (nos. 71701181, 71771075, and 71331002), the Social Science Foundation of Ministry of Education of China (no. 16YJC630094), and the Natural Science Foundation of Zhejiang Province of China (LQ17G010002 and LY18G010010).

\section{References}

[1] A. E. Akgün, H. Keskin, J. C. Byrne, and Ö. Ö. Ilhan, “Complex adaptive system mechanisms, adaptive management practices, and firm product innovativeness," ReD Management, vol. 44, no. 1, pp. 18-41, 2014.
[2] M. Gell-Mann, The quark and the jaguar, W. H. Freeman and Company, New York, 1994.

[3] R. Chiva-Gomez, "Repercussions of complex adaptive systems on product design management," Technovation, vol. 24, no. 9, pp. 707-711, 2004.

[4] Y. Hsu, "Design innovation and marketing strategy in successful product competition," Journal of Business \& Industrial Marketing, vol. 26, no. 4, pp. 223-236, 2011.

[5] A. Vuruskan, T. Ince, E. Bulgun, and C. Guzelis, "Intelligent fashion styling using genetic search and neural classification," International Journal of Clothing Science and Technology, vol. 27, no. 2, pp. 283-301, 2015.

[6] P. Y. Mok, J. Xu, X. X. Wang, J. T. Fan, Y. L. Kwok, and J. H. Xin, "An IGA-based design support system for realistic and practical fashion designs," Computer-Aided Design, vol. 45, no. 11, pp. 1442-1458, 2013.

[7] R. Dou, C. Zong, and G. Nan, "Multi-stage interactive genetic algorithm for collaborative product customization," KnowledgeBased Systems, vol. 92, pp. 43-54, 2016.

[8] A. M. Brintrup, J. Ramsden, H. Takagi, and A. Tiwari, "Ergonomic chair design by fusing qualitative and quantitative criteria using interactive genetic algorithms," IEEE Transactions on Evolutionary Computation, vol. 12, no. 3, pp. 343-354, 2008.

[9] R. Dou, C. Zong, and M. Li, "An interactive genetic algorithm with the interval arithmetic based on hesitation and its application to achieve customer collaborative product configuration design," Applied Soft Computing, vol. 38, pp. 384-394, 2016.

[10] P. D. Liu and X. C. Yu, "2-Dimension uncertain linguistic power generalized weighted aggregation operator and its application in multiple attribute group decision making," Knowledge-Based Systems, vol. 57, no. 1, pp. 69-80, 2014.

[11] P. Liu and X. Liu, "Multiattribute group decision making methods based on linguistic intuitionistic fuzzy power Bonferroni mean operators," Complexity, Art. ID 3571459, 15 pages, 2017.

[12] C. Kahraman, S. C. Onar, and B. Oztaysi, "Fuzzy multicriteria decision-making: a literature review," International Journal of Computational Intelligence Systems, vol. 8, no. 4, pp. 637-666, 2015.

[13] A. Mardani, A. Jusoh, and E. K. Zavadskas, "Fuzzy multiple criteria decision-making techniques and applications-two decades review from 1994 to 2014," Expert Systems with Applications, vol. 42, no. 8, pp. 4126-4148, 2015.

[14] Z. Tao, X. Liu, H. Chen, and L. Zhou, "Using New Version of Extended t-Norms and s-Norms for Aggregating Interval Linguistic Labels," IEEE Transactions on Systems Man \& Cybernetics Systems, pp. 1-15, 2016.

[15] L. Martínez and F. Herrera, "An overview on the 2-tuple linguistic model for computing with words in decision making: extensions, applications and challenges," Information Sciences, vol. 207, pp. 1-18, 2012.

[16] E. Herrera-Viedma and A. G. López-Herrera, "A model of an information retrieval system with unbalanced fuzzy linguistic information," International Journal of Intelligent Systems, vol. 22, no. 11, pp. 1197-1214, 2007.

[17] L. Martínez, M. Espinilla, J. Liu, L. G. Pérez, and P. J. Sánchez, "An evaluation model with unbalanced linguistic information applied to olive oil sensory evaluation," Journal of MultipleValued Logic and Soft Computing, vol. 15, no. 2-3, pp. 229-251, 2009.

[18] F. Herrera, E. Herrera-Viedma, and L. Martínez, "A fuzzy linguistic methodology to deal with unbalanced linguistic term 
sets," IEEE Transactions on Fuzzy Systems, vol. 16, no. 2, pp. 354$370,2008$.

[19] D. Meng and Z. Pei, "On weighted unbalanced linguistic aggregation operators in group decision making," Information Sciences, vol. 223, pp. 31-41, 2013.

[20] Y. Dong, C.-C. Li, and F. Herrera, "An optimization-based approach to adjusting unbalanced linguistic preference relations to obtain a required consistency level," Information Sciences, vol. 292, pp. 27-38, 2015.

[21] B. Farhadinia, "Correlation for dual hesitant fuzzy sets and dual interval-valued hesitant fuzzy sets," International Journal of Intelligent Systems, vol. 29, no. 2, pp. 184-205, 2014.

[22] Y. B. Ju, X. Y. Liu, and S. H. Yang, "Interval-valued dual hesitant fuzzy aggregation operators and their applications to multiple attribute decision making," Journal of Intelligent \& Fuzzy Systems: Applications in Engineering and Technology, 2013.

[23] B. Zhu, Z. Xu, and M. Xia, "Dual hesitant fuzzy sets", Journal of Applied Mathematics, vol. 2012, Article ID 879629, 13 pages, 2012.

[24] X. Ma, P. Wu, L. Zhou, H. Chen, T. Zheng, and J. Ge, "Approaches Based on Interval Type-2 Fuzzy Aggregation Operators for Multiple Attribute Group Decision Making," International Journal of Fuzzy Systems, vol. 18, no. 4, pp. 697715, 2016.

[25] P. Liu, L. Zhang, X. Liu, and P. Wang, "Multi-valued neutrosophic number bonferroni mean operators with their applications in multiple attribute group decision making," International Journal of Information Technology \& Decision Making, vol. 15, no. 5, pp. 1181-1210, 2016.

[26] P. Liu, "A weighted aggregation operators multi-attribute group decision-making method based on interval-valued trapezoidal fuzzy numbers," Expert Systems with Applications, vol. 38, no. 1, pp. 1053-1060, 2011.

[27] Z. S. Xu, "EOWA and EOWG operators for aggregating linguistic labels based on linguistic preference relations," International Journal of Uncertainty, Fuzziness and Knowledge-Based Systems, vol. 12, no. 6, pp. 791-810, 2004.

[28] P. Liu and F. Teng, "Multiple criteria decision making method based on normal interval-valued intuitionistic fuzzy generalized aggregation operator," Complexity, vol. 21, no. 5, pp. 277290, 2016.

[29] P. Liu, S.-M. Chen, and J. Liu, "Multiple attribute group decision making based on intuitionistic fuzzy interaction partitioned Bonferroni mean operators," Information Sciences, vol. 411, pp. 98-121, 2017.

[30] X. Qi, C. Liang, and J. Zhang, "Generalized cross-entropy based group decision making with unknown expert and attribute weights under interval-valued intuitionistic fuzzy environment," Computers \& Industrial Engineering, vol. 79, pp. 52-64, 2015.

[31] R. R. Yager, “The power average operator," IEEE Transactions on Systems, Man, and Cybernetics: Systems, vol. 31, no. 6, pp. 724731, 2001.

[32] L. G. Zhou and H. Y. Chen, "A generalization of the power aggregation operators for linguistic environment and its application in group decision making," Knowledge-Based Systems, vol. 26, pp. 216-224, 2012.

[33] L. Zhou, H. Chen, and J. Liu, "Generalized power aggregation operators and their applications in group decision making," Computers \& Industrial Engineering, vol. 62, no. 4, pp. 989-999, 2012.
[34] R. R. Yager, "Induced aggregation operators," Fuzzy Sets and Systems, vol. 137, no. 1, pp. 59-69, 2003.

[35] J. M. Merigó and M. Casanovas, "Decision-making with distance measures and induced aggregation operators," Computers \& Industrial Engineering, vol. 60, no. 1, pp. 66-76, 2011.

[36] Z. Su, Z. Xu, H. Liu, and S. Liu, "Distance and similarity measures for dual hesitant fuzzy sets and their applications in pattern recognition," Journal of Intelligent \& Fuzzy Systems: Applications in Engineering and Technology, vol. 29, no. 2, pp. 731-745, 2015.

[37] Z. S. Xu and M. Xia, "Distance and similarity measures for hesitant fuzzy sets," Information Sciences, vol. 181, no. 11, pp. 2128-2138, 2011.

[38] Y. Dong, C.-C. Li, and F. Herrera, "Connecting the numerical scale model to the unbalanced linguistic term sets," in Proceedings of the 2014 IEEE International Conference on Fuzzy Systems, FUZZ-IEEE 2014, pp. 455-462, China, July 2014.

[39] V. Torra, "Hesitant fuzzy sets," International Journal of Intelligent Systems, vol. 25, no. 6, pp. 529-539, 2010.

[40] C. Lin and C. Twu, "Combination of a fuzzy analytic hierarchy process (FAHP) with the Technique for Order Preference by Similarity to Ideal Solution (TOPSIS) for fashion design scheme evaluation," Textile Research Journal, vol. 82, no. 10, pp. 10651074, 2012.

[41] J. Zhang, G. G. Hegde, J. Shang, and X. Qi, "Evaluating emergency response solutions for sustainable community development by using fuzzy multi-criteria group decision making approaches: IVDHF-TOPSIS and IVDHF-VIKOR," Sustainability, vol. 8, no. 4, article no. 291, 2016.

[42] Z. Xu, "Intuitionistic fuzzy aggregation operators," IEEE Transactions on Fuzzy Systems, vol. 15, no. 6, pp. 1179-1187, 2007.

[43] R. R. Yager, "Quantifier guided aggregation using OWA operators," International Journal of Intelligent Systems, vol. 11, no. 1, pp. 49-73, 1996. 


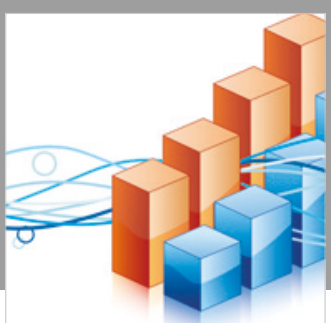

Advances in

Operations Research

\section{-n-m}
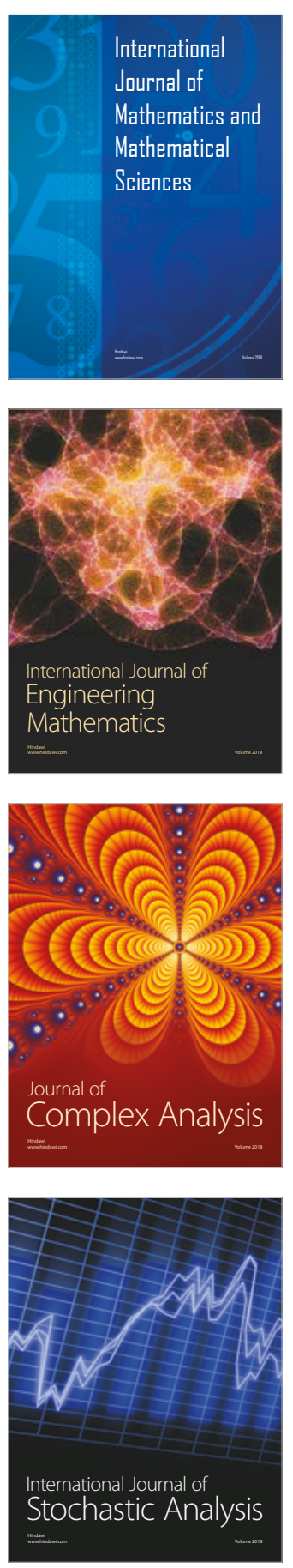
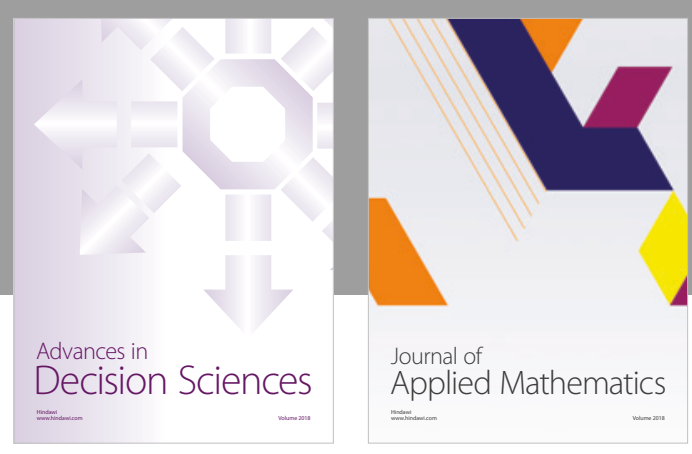

Journal of

Applied Mathematics
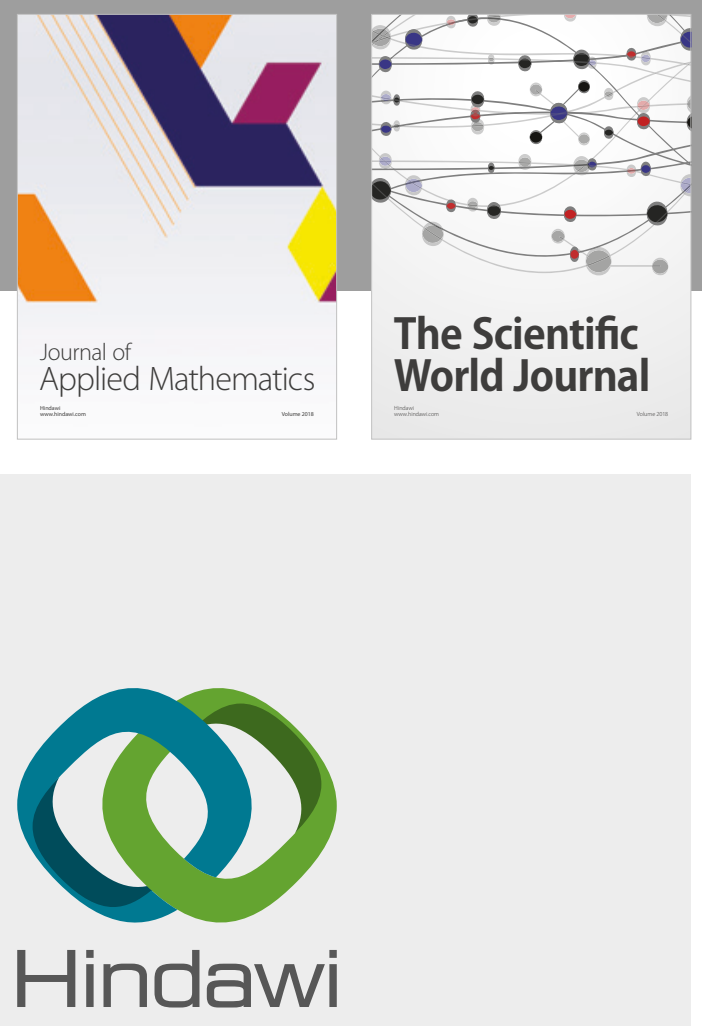

Submit your manuscripts at

www.hindawi.com

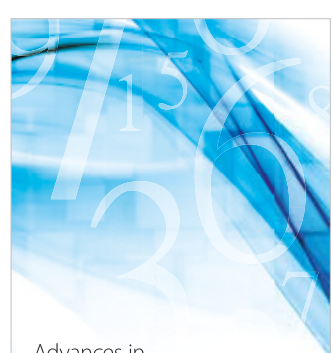

Advances in
Numerical Analysis
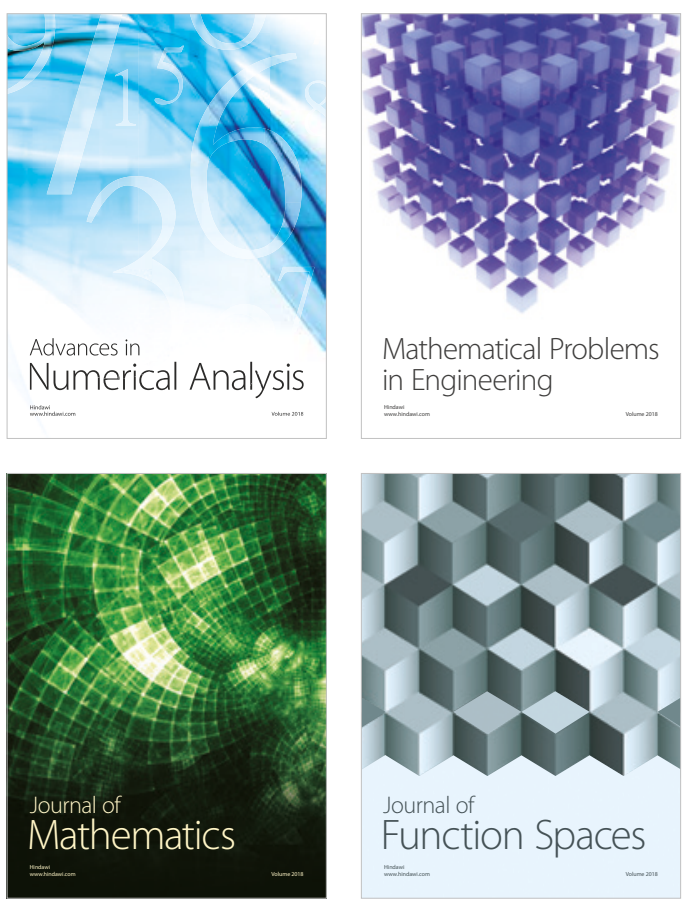

Mathematical Problems in Engineering

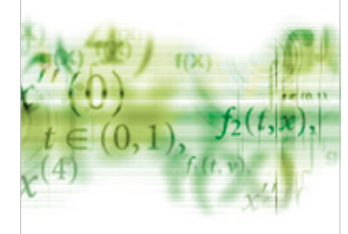

International Journal of

Differential Equations

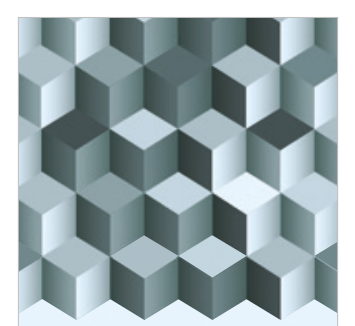

Journal of

Function Spaces
The Scientific

World Journal

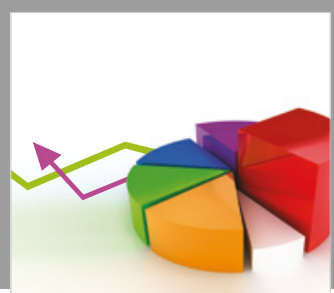

Journal of

Probability and Statistics
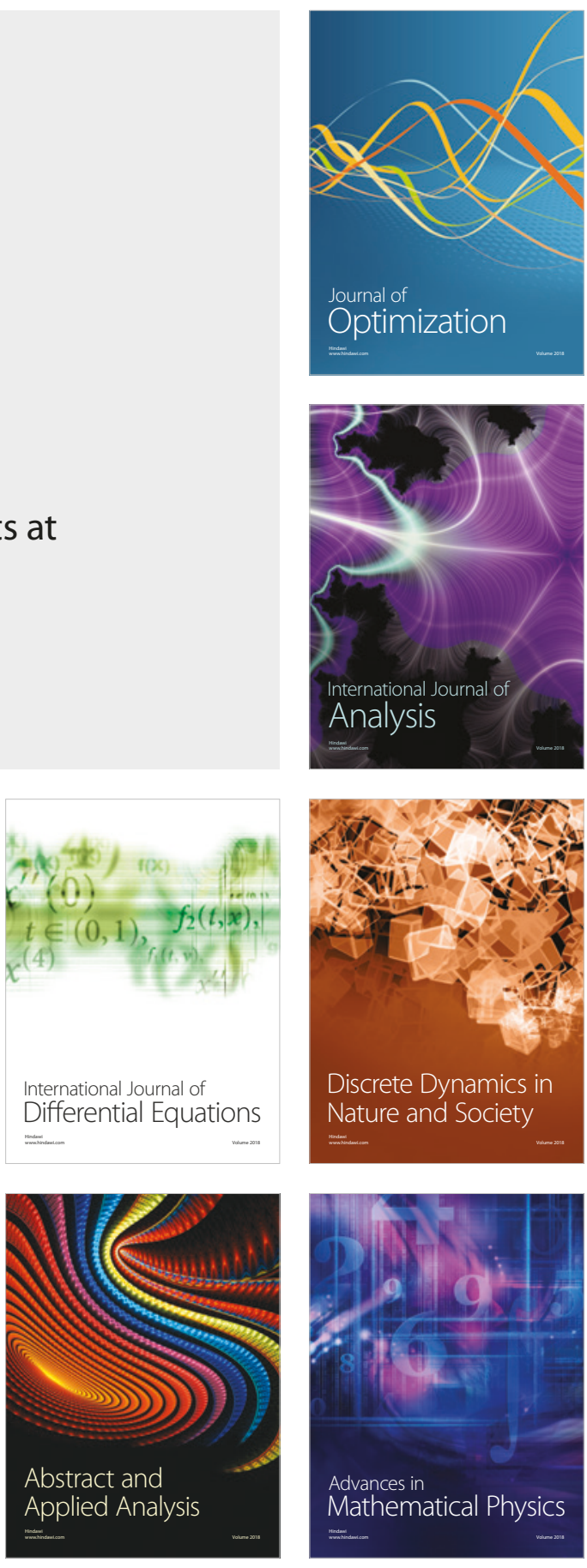